\title{
A Review on Si-Based Ceramic Matrix Composites and their Infiltration Based Techniques
}

\author{
N. Radhika ${ }^{1}$ M. Sathish ${ }^{1}$
}

Received: 25 October 2021 / Accepted: 10 February 2022 / Published online: 2 March 2022

(c) The Author(s), under exclusive licence to Springer Nature B.V. 2022

\begin{abstract}
This review paper aims to look at silicon-based ceramic matrix composites and infiltration-based approaches for them. There are many different types of infiltration-based manufacturing processes, each with its own set of features. The best technique is chosen depending on the needs and desired attributes. With these considerations in mind, any type of infiltration might be selected to meet the requirements. Silicon-based ceramics has been highly used in the fields of aerospace, medical, automobile, electronics, and other various industries so it is important to study about their applications as well. This review outlines the evolution of composites from early $7000 \mathrm{BCE}$ to composites today and discussed about various infiltration techniques for manufacturing silicon based ceramic matrix composites. This article also gives the comprehensive review of general characteristics and mechanical properties of silicon-based composites used in a variety of engineering sectors. The application section entails the wide range of engineering fields with consideration of infiltration techniques, which would be helpful for researchers to study and correlate the different infiltration techniques for end applications.
\end{abstract}

Keywords Ceramic composites $\cdot$ Silicon carbide $\cdot$ Silicon nitride $\cdot$ Silicon dioxide $\cdot$ Infiltration techniques $\cdot$ Engineering applications

\section{Introduction}

Silicon-based ceramics are specifically attractive components due to their diverse optic and electro-optic, magnetic, thermal, mechanical, and electrical properties. The most commonly preferred Si-based ceramics such as silicon carbide $(\mathrm{SiC})$, silicon nitride $\left(\mathrm{Si}_{3} \mathrm{~N}_{4}\right)$, and silicon dioxide $\left(\mathrm{SiO}_{2}\right)$, have a broad range of applications in various fields like chemical industries, aluminium processing, fossil fuel extraction, and manufacturing of solar panel, due to its combined special properties and applications. This Siliconbased ceramics and composites are excellent candidates for structural components in heat engines and heat exchangers. Possibilities of common applications from a wide variety of industries are considered for each material type, while the property characteristic is taken into consideration [1,2]. The $\mathrm{SiC}$ fiber-reinforced $\mathrm{SiC}$ matrix $\left(\mathrm{SiC}_{\mathrm{f}} / \mathrm{SiC}\right)$ composite

N. Radhika

n_radhika1@cb.amrita.edu

1 Department of Mechanical Engineering, Amrita School of Engineering, Amrita Vishwa Vidyapeetham, Coimbatore, India has been widely employed in high-velocity and high-temperature applications such as nozzles, rocket engines, aerospace applications, braking discs, nuclear reactors, and the semiconductor industry. Thermodynamic stability, creep resistance, low density, notable wear resistance, oxidation, corrosion resistance and exceptional damage tolerance under difficult conditions are all advantages of $\mathrm{SiC}_{\mathrm{f}} / \mathrm{SiC}$ composites over typical metallic alloys and monolithic ceramics [3, 4]. A multitude of processes is utilized to make $\mathrm{SiC}$ ceramics, depending on the production cost, size, and shape. Hot pressing, Chemical Vapor Infiltration (CVI), Chemical Liquid-Vapor Deposition (CLVD), Liquid Silicon Infiltration (LSI), and Polymer Infiltration and Pyrolysis (PIP) are examples of these techniques [5-7].

Ceramic Matrix Composites (CMCs) have become a more essential and cost-effective material in recent years. The name "ceramics" refers to a diverse group of materials, each with its own set of characteristics. Clay ware, pottery, and refractories are examples of traditional ceramics. Most materials based on Magnesia $(\mathrm{MgO})$, Alumina $\left(\mathrm{Al}_{2} \mathrm{O}_{3}\right)$ and $\mathrm{SiO}_{2}$ belong to the oxide group of ceramics [8]. Low electrical conductivity, low thermal conductivity, and chemical inertness are only a few of the benefits of 
ceramics. Ceramic's mechanical qualities are determined by their macroscopic and atomic physical structures. Ceramics have a wide range of qualities, ranging from isotropic and dense glasses to bricks with a mixture of crystalline glassy phases, pores, and fissures [9]. CMCs find their application in important industries such as aerospace, energy, and automobiles. CMCs are a promising future solution in industrial sectors; for example, in the aerospace sector, they have been used as a substitute for nickel alloys due to their superior heat resistance and reduced weight. Electric vehicles have grown in popularity as part of sustainable development, so in order to make electric vehicles more successful, researchers and scientists say that reducing weight can increase run time, for which CMCs are an excellent substitute. CMCs made of $\mathrm{Al}_{2} \mathrm{O}_{3}$ and zirconia is used in biomedical applications such as orthopaedic device ball heads, finger joints, hip prostheses, and dental restorative materials. They also have a lot of potential in the medical field. CMCs can be used to make printed circuit boards in the electronics sector that require high heat resistance. CMCs for power turbines are used in industrial applications to assist reduce pollution and electricity consumption. Figure 1 outlines the evolution of composites from early $7000 \mathrm{BCE}$ to the present-day composites have become inevitable in our day-to-day life.

Non-oxide ceramics including $\mathrm{SiC}$ and oxide ceramics including $\mathrm{SiO}_{2}$ and $\mathrm{Al}_{2} \mathrm{O}_{3}$ are preferably used [10-12]. Due to their mechanical endurance at severe temperatures, non-oxide ceramic composites, particularly SiC-based CMCs like Carbon reinforced $\mathrm{SiC}(\mathrm{C} / \mathrm{SiC})$ is very popular [13]. Several researchers have used Raman Spectroscopy or micro-hardness tests to investigate thermal expansion and processing temperature differences [14-17]. In ceramic structures, there are substantial levels of tensile or compressive residual stresses in a wide range of ceramic composites. Furthermore, due to features such as hardness, brittleness, orthotropy, mechanical and thermal behaviour, and the heterogeneous nature of CMCs, the machinability of ceramic composites is difficult. They are known for their high-temperature applications and excellent hardness. Hardness refers to a material's mechanical qualities. High mechanical and thermal cutting loads are produced by hard materials. Harder materials like $\mathrm{SiC}$ are frequently employed as a matrix and reinforcement in CMCs. Thus, CMCs tend to have high hardness with lower values of fracture toughness, which indicates the brittle nature of CMCs. However, the hardness and fracture toughness should be utilized simultaneously to compare the importance of these parameters in different materials. Figure 2 entails the conceptual representation of CMCs and its properties.

A most important property of ceramics is brittleness, this hampers the application of ceramics under conditions of shock or load [18]. The nature of bonding of the continuous fibers along with the matrix determines the brittleness in ceramics leading to its failure [19]. Creep generation is too high in unexpected loading in oxide ceramics. In glass ceramics, the orientation of the fibers dictates the fracture and the rate of crack growth within the composite. Defect of the composite easily occurs at the interphase of the material. When the stress is applied in the direction of the fiber, these micro-cracks spread in the direction perpendicular to the fiber, introducing brittleness to the fibers and rendering the CMCs prone to failure [20]. Each phase of the composite has its failure properties influencing the failure of the material [21]. The structure of the review paper is organized as follows:
Fig. 1 Graphical representation of evolution of composite materials

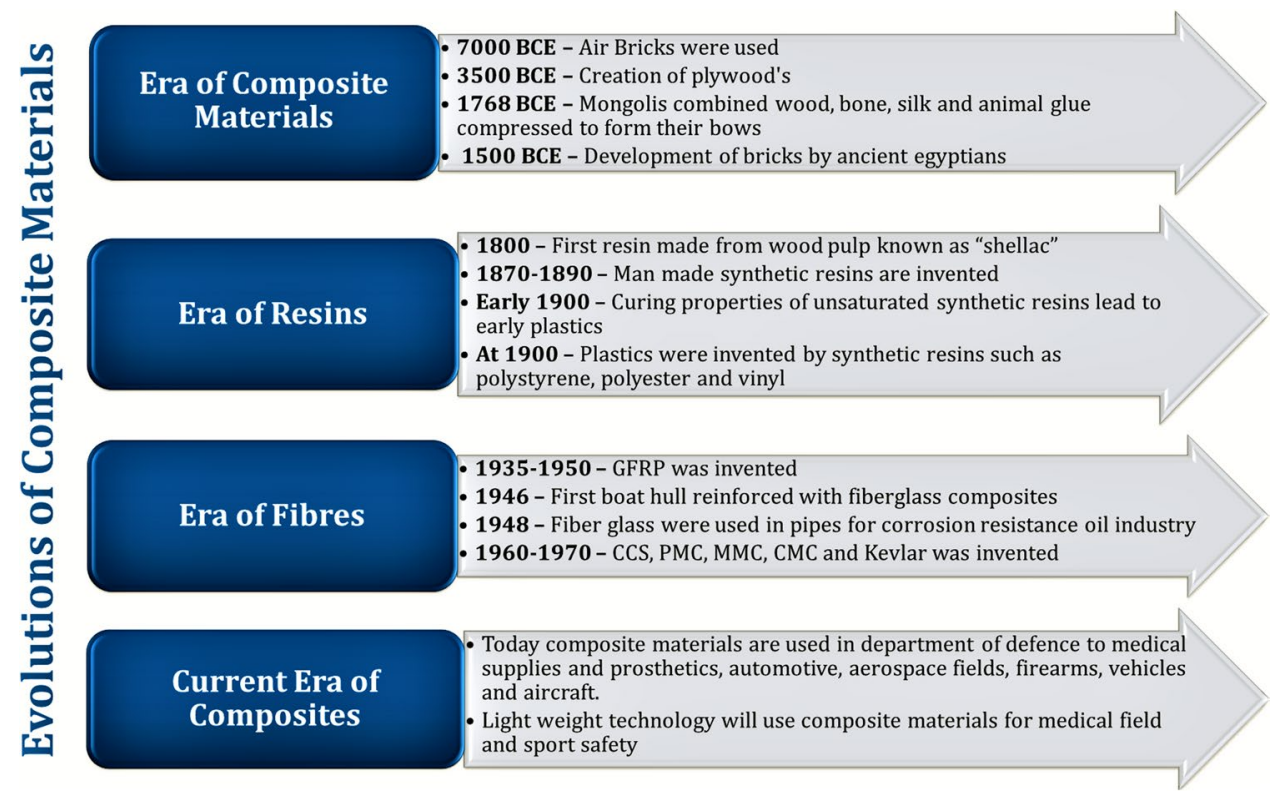


Fig. 2 Conceptual representation of CMCs and its properties

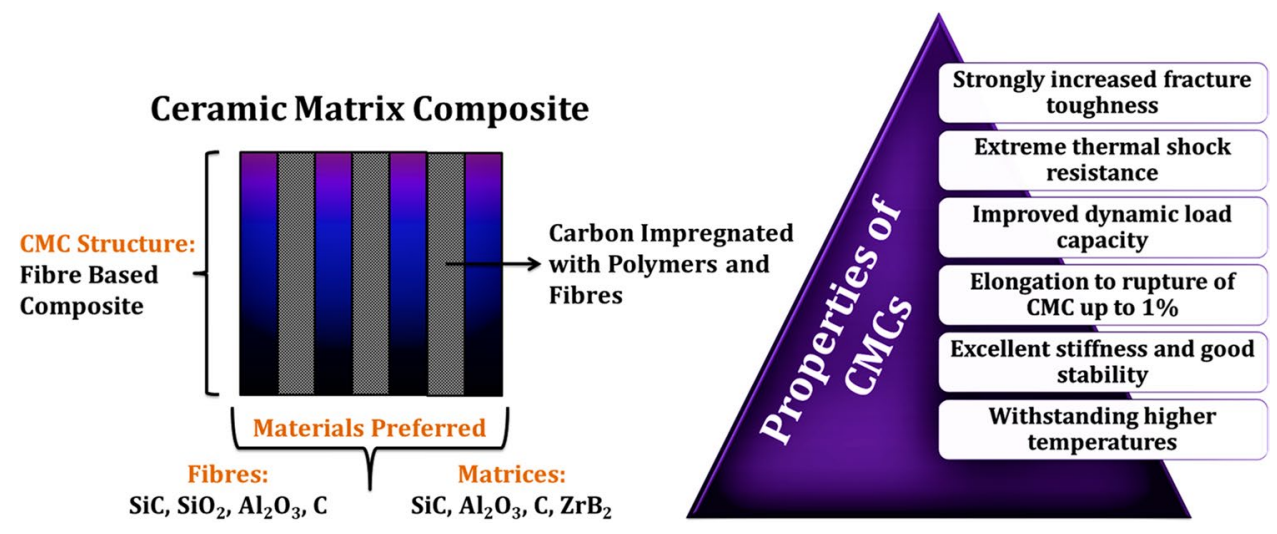

- The silicon-based ceramic composites are described in the first part. The behaviour of silicon-based composites such as $\mathrm{SiC}, \mathrm{Si}_{3} \mathrm{~N}_{4}$ and $\mathrm{SiO}_{2}$ is reviewed, as well as the mechanical properties and their numerous domains of applications are also explored.

- The next section discusses the different infiltration techniques that are used to fabricate Silicon-based CMCs. This section briefly discusses the general aims, schematic illustrations, and scopes of this infiltration method for researchers. The significant effect of PIP process and the role of fillers in pyrolysis, as well as the CVI process, which is derived directly from the Chemical Vapor Deposition (CVD) process and the importance of CVI in manufacturing high purity composites, Reactive Melt Infiltration (RMI) used to manufacture gas turbine parts, Sol-gel infiltration, and Slurry Infiltration (SI) are briefly discussed. The overview of several infiltration techniques is discussed, including the specific purpose, preferable ceramics, preferable reinforcements and matrices, benefits and drawbacks with its inferences.

- The possibilities of Silicon-based composites in automobiles, aircraft, medical, industrial, military, and electronics are briefly reviewed in the next part, which includes schematic illustrations coupled with several sectors of applications for infiltration and combined infiltration processes.

- Furthermore, the future need for SiC-based composites in many industries is examined, as well as their use in the biomedical field, where they are employed in the development of biomedical devices that may be implanted into any part of the body. CMCs revenue share $\%$ and future research potentials are also mentioned.

\section{Silicon-Based Ceramic Composites}

Silicon-based materials are known for their high-temperature applications usually noticed in aerospace and automotive applications [5]. $\mathrm{SiC}, \mathrm{SiO}_{2}$ and $\mathrm{Si}_{3} \mathrm{~N}_{4}$ form the most popular matrix choice for silicon-based ceramic composites because of their high strength and high-temperature properties often used in the form of the preform, although these materials are used as matrices and they are also used as reinforcements in the form of whiskers, long fibers, particles, etc., some of these materials are further reviewed below [22].

\subsection{Silicon Carbide}

This popular non-oxide ceramic has long been acting as both matrix and reinforcement, usually finding its applications in silicon-based CMCs such as turbine disks, turbopump rotors, nozzle exit ramps for rockets engines, pistons, bearings, etc., [23, 24]. The behavior of $\mathrm{SiC}$ as a reinforcement in the form of fiber is observed when bonded with Lithium Alumino-silicate (LAS). The LAS-SiC ceramic composite demonstrated properties of high strength and excellent toughness at $1000^{\circ} \mathrm{C}$ with good elevated creep resistance but the properties of reinforcement highly depend upon the ply orientation of the $\mathrm{SiC}$ fiber in correspondence to the matrix [25]. The development of CMCs automotive power-train components was attained with superior mechanical properties including good thermal shock resistance and particle impact resistance. Different testing methods are performed to know about the characteristic evolution of the CMCs. For the ceramic gas turbine engine components, the backplate made of Carbon fiber-reinforced $\mathrm{SiC}\left(\mathrm{C}_{\mathrm{f}} / \mathrm{SiC}\right)$ and Sialon (SiAlON), the orifice liner and inner scroll support are manufactured using $\mathrm{C}_{\mathrm{f}} / \mathrm{SiC}$ and $\mathrm{SiC}$ reinforced with $\mathrm{SiN}-\mathrm{C}$ composites which withstood high-temperature tests capable of withstanding above $1200{ }^{\circ} \mathrm{C}$ [26]. Figure 3 shows the various fields of applications for $\mathrm{SiC}$ ceramic composites. $\mathrm{SiC}$ ceramics materials are hard to machine, the machinability properties of $\mathrm{SiC}$ can be improved when reinforced with $\mathrm{C}_{\mathrm{f}}$, the properties were analyzed by comparing both $\mathrm{SiC}$ and $\mathrm{C}_{\mathrm{f}} / \mathrm{SiC}$ when subjected to grinding forces hence demonstrating that $\mathrm{C}_{\mathrm{f}} / \mathrm{SiC}$ required much lesser forces than $\mathrm{SiC}$. The $\mathrm{C}_{\mathrm{f}}$ reinforcements when combined with $\mathrm{SiC}$ have also improved 

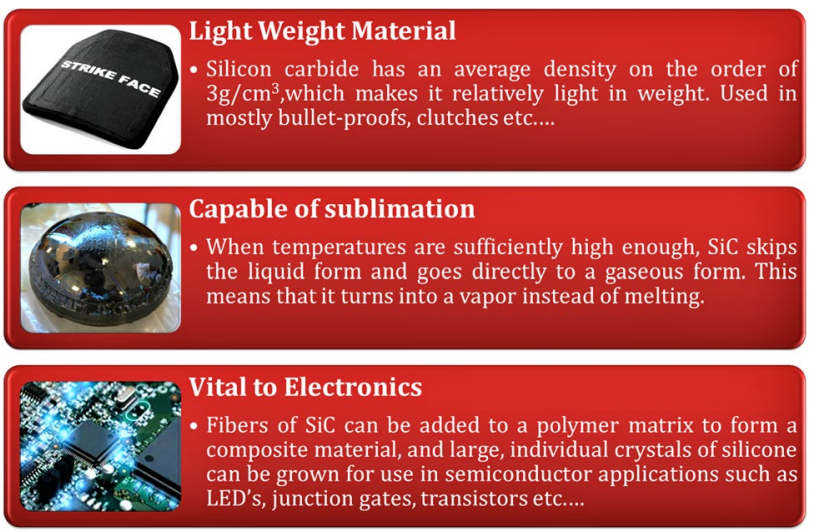

Fig. 3 Fields of applications of SiC-based ceramic composites

\& enhanced the surface finish, resistance to brittleness and have made SiC easier to machine [24, 27-29].

\subsection{Silicon Nitride}

This $\mathrm{Si}_{3} \mathrm{~N}_{4}$ is intriguing CMCs with a small market. Component costs and process unpredictability are the main roadblocks to commercialization [30]. To assist densify $\mathrm{Si}_{3} \mathrm{~N}_{4}$ ceramics and enhance phase change, gas pressure sintering or hot pressing is necessary [31]. While manufactured by pressure less sintering, ceramics like $\mathrm{Si}_{3} \mathrm{~N}_{4}$-Barium Alumino-silicate $\left(\mathrm{Si}_{3} \mathrm{~N}_{4}\right.$-BAS) display good mechanical characteristics. During cooling, the BAS matrix within crystallizes into a hexagonal phase, which offers excellent high-temperature characteristics. However, to reach practical application, more toughness development is required [32, 33]. Several attempts have been undertaken in recent decades to improve the microstructure of $\mathrm{Si}_{3} \mathrm{~N}_{4}$ to increase its toughness. $\mathrm{Si}_{3} \mathrm{~N}_{4}$ ceramics are composed of elongated $\beta-\mathrm{Si}_{3} \mathrm{~N}_{4}$ grains in a fine-grained matrix with amorphous or partially crystalline grain boundary phases. The elongated grains, like whiskers, work to strengthen the matrix and increase the ceramic's fracture resistance by activating crack wake toughening mechanisms. The fracture toughness of $\mathrm{Si}_{3} \mathrm{~N}_{4}$ grains at room temperature is determined by their size and shape, as long as an intergranular fracture mode is provided by a weak interface between $\mathrm{Si}_{3} \mathrm{~N}_{4}$ and the grain boundary phase. Fracture resistance increases with crack extension in coarse-grained microstructures. Along with sintering processes, additional common toughening mechanisms were fracture bridging, crack deflection, and pull-out. Varied sintering techniques were utilized with different sintering profiles, resulting in different mechanical characteristics of $\mathrm{Si}_{3} \mathrm{~N}_{4}$ [34-44]. Figure 4 shows the fields of applications for $\mathrm{Si}_{3} \mathrm{~N}_{4}$ ceramic composites. $\mathrm{As} \mathrm{Si}_{3} \mathrm{~N}_{4}$ lacks toughness, many efforts have been made to improve it like self-reinforcement and incorporation of particles and whiskers [45-47]. SiC whiskers

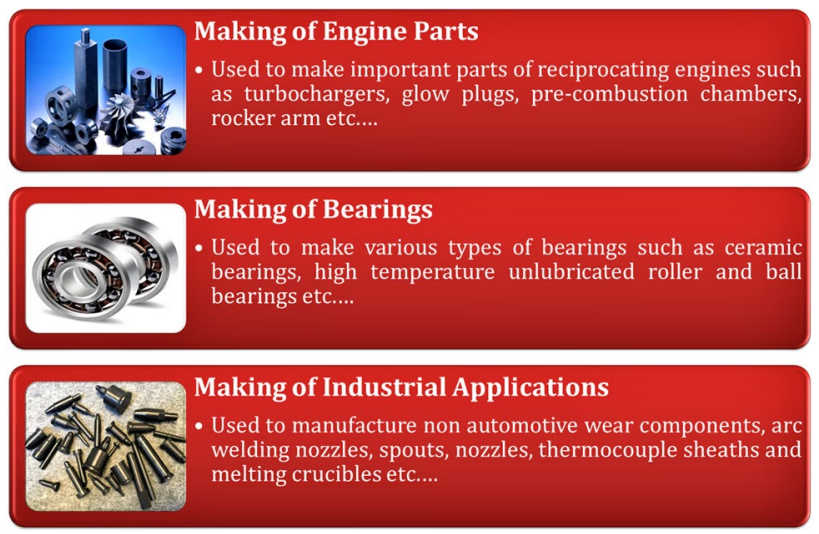

Fig. 4 Fields of applications of $\mathrm{Si}_{3} \mathrm{~N}_{4}$ based ceramic composites

were added to $\mathrm{Si}_{3} \mathrm{~N}_{4}$ matrix layers to strengthen them, and $\mathrm{Si}_{3} \mathrm{~N}_{4}$ was inserted into the hexagonal Boron Nitride (BN) layers to change the bonding strength of the bonding layers to improve laminated $\mathrm{Si}_{3} \mathrm{~N}_{4} / \mathrm{BN}$ [48].

$\mathrm{SiO}_{2}$ fiber-reinforced $\mathrm{Si}_{3} \mathrm{~N}_{4}$ composite, which forms the part of the Continuous Fiber CMCs (CFCMCs) are made from a three-dimensional angle-interlocked fabric woven preform $\left(\mathrm{SiO}_{2}\right.$ fiber $)$ which is further vacuum infiltrated with ammonia at $800{ }^{\circ} \mathrm{C}$. The crystallization behavior of this composite conveys that $\mathrm{Si}_{3} \mathrm{~N}_{4}$-based composites become weak due to the stretching of bonds which in turn weakens the bond when subjected to an elevated temperature above $1600{ }^{\circ} \mathrm{C}[49,50]$. $\mathrm{SiC}$ and $\mathrm{Si}_{3} \mathrm{~N}_{4}$ are used for high-temperature purposes due to their excellent mechanical properties [51] The mechanical properties of $\mathrm{Si}_{3} \mathrm{~N}_{4}$ and $\mathrm{SiC}$ brittleness of the ceramic components limit their application; they can be fabricated through CVI and hot isostatic pressing under higher temperature and pressure conditions. The flexural strength, fracture toughness, and restrained strength ratios differ along with the change in the temperature. The presence of high-strength filaments in the matrix without adhesion was demonstrated in $\mathrm{SiC}$ matrix composites reinforced with unidirectional $\mathrm{SiC}$ monofilaments, which improved the fracture toughness of the composite. Monofilaments with carbon-rich surface layers effectively prevented filament adhesion in $\mathrm{SiC}$ reinforced $\mathrm{Si}_{3} \mathrm{~N}_{4}$ matrix composites, increasing the fracture toughness of the composites [52]

\subsection{Silicon dioxide}

The silicon oxides are represented in the molecular composition $\mathrm{SiO}_{2}$ that is most often found naturally as quartz and in a variety of living species. Silica is a key component of sand in many locations throughout and one of the most complicated and plentiful material families, occurring as both a mineral constituent and a manufactured product. Fused quartz, fumed silica, silica gel, and aerogels are all 
good examples of this compound. It's utilised as construction materials, semiconductors, and foods and pharmaceuticals as an ingredient. This nano $\mathrm{SiO}_{2}$ is used as filler material in natural fibres and reinforcing with other reinforcing substances to improve dynamic characteristics respectively. Because of its minimal price, low density, easy accessibility, and exceptional qualities, nano $\mathrm{SiO}_{2}$ has been chosen as a filler substance [53].

Advanced materials based on CMCs, such as $\mathrm{SiO}_{2}, \mathrm{Al}_{2} \mathrm{O}_{3}$, $\mathrm{SiC}$ have been highlighted as a crucial material system for enhancing the thrust-to-weight ratios of higher performance aviation engines. The current research reviews related existing publications and our expertise in this sector to discuss the possible use of CMC to aviation structures. It includes material needs for aviation as well as developments in aeroengine materials efficiency connected to ceramic composites. [54]. Also, the research was conducted with the influence of nano-silica on the mechanical characteristics of micro-steel fibres reinforced with fly ash ceramic composites. The micro-steel fibres are remained constant while the fly ash and nano-silica concentrations are varied. The inclusion of nano-silica greatly improved the mechanical characteristics and morphology of micro-steel fibre reinforced composites by forming a stronger matrix and improving the intermediate regions, according to the results of testing. The optimum quantity of nano-silica to use in composite is $2 \%$, according to the study findings [55]. Figure 5 shows the fields of applications of $\mathrm{SiO}_{2}$ based ceramic composites.

Because of its strong strength, flexibility, outstanding hardness, lower density, exceptional wear rate, and reduced thermal expansion coefficient, continuous carbon-fibre-reinforcement $\mathrm{Li}_{2} \mathrm{O}-\mathrm{Al}_{2} \mathrm{O}_{3}-\mathrm{SiO}_{2}\left(\mathrm{C}_{\mathrm{f}} / \mathrm{LAS}\right.$ composites) offer extreme temperature properties. $\mathrm{C}_{\mathrm{f}} / \mathrm{LAS}$ composite has attractive properties in increased temperature applications due to their superior thermo-mechanical qualities, such as thermal exchangers, elevated temperature windows, and laser devices. [56]. In another study, the CVI was
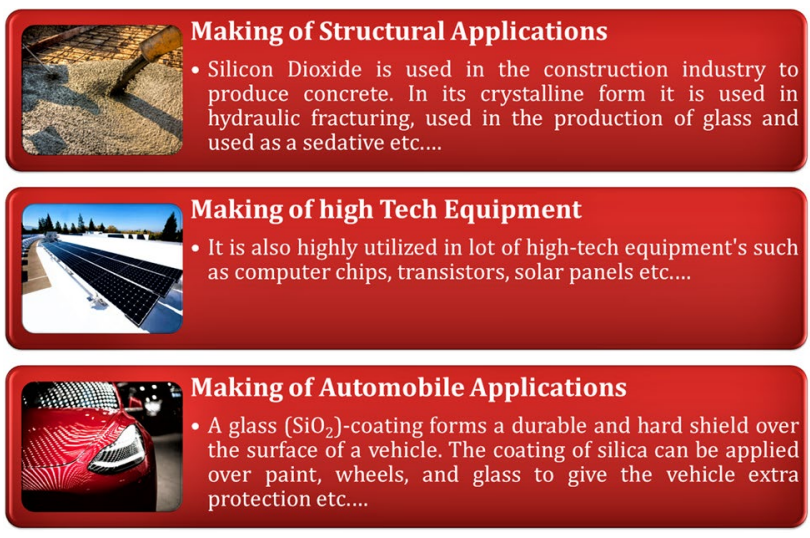

Fig. 5 Fields of applications of $\mathrm{SiO}_{2}$ based ceramic composites used to create Hi-Nicalon/SiC mini-composite samples with three oxide interphase layers (amorphous $\mathrm{SiO}_{2}$, monoclinic $\mathrm{ZrO}_{2}$, and amorphous $\mathrm{SiO}_{2}$ ). In the perspective of building ecologically resisting surfaces for ceramic composites, the possible benefits and risks connected with this multi-layer oxides interfacial method were examined. [57]. Relatively, the study conducted on plasma sprayed $\mathrm{SiO}_{2}$ coating was found to result in a substantial rise in maximal pull-out effort, revealing improved bonding strength and improving interconnections between upgraded carbon fibre yarns and the concrete matrices. Also, research conducted on the combination of $\mathrm{SiO}_{2}-\mathrm{TiO}_{2} /$ carbon fibre with $\mathrm{TiO}_{2} / \mathrm{C}$ composite coating layer exhibit improved electrochemical behaviour and greater charging capacities [58]. In another investigation, by combining the two ceramic oxide materials like $\mathrm{ZnO} / \mathrm{SiO}_{2}$ composite coatings has enhanced wear resisting property, improved hydrophobic durability, adhesion bonding and lower porosity is achieved in the paper mulch film respectively [59]. Table 1 shows the general and mechanical properties of silicon based ceramics with its applications.

\section{Infiltration Methods of Ceramic Matrix Composites}

Infiltration is a liquefied type manufacturing process in which a preform reinforcing materials such as ceramic powders, fibres, weaves, and other porous materials are impregnated eventually and fills the gaps in the molten metal matrices. One of the most important processes in the manufacturing of composites by infiltration techniques is the creation of a pore preforms with appropriate mechanical performance, consistent pores dispersion, pores dimension, and porous concentration. These infiltration procedures are often used to make CMCs reinforced with long fibers. The ceramic matrix is created by infiltrating a fluid (gaseous or liquid) into the fiber structure in this category of manufacturing processes (either woven or non-woven). The surfaces of the reinforcing fibers are coated with debonding interphase, which bonds weakly at the interface between matrix materials and the fibre before infiltration with a ceramic derived fluid. Weak bonding permits fibers to slide about in the matrix thus avoiding brittle fractures. Figure 6 illustrates the classification of infiltration methods of CMCs fabrication.

\subsection{Polymer Infiltration and Pyrolysis}

PIP is a technique of fabricating ceramic matrix that involves infiltrating a low viscous polymer into the reinforcement of ceramic structure such as fabrics, and then pyrolysis, which involves heating the polymer precursor in the lack of oxygen until it breaks down and changes into a ceramic component. This is an infiltrating process of a ceramic precursor 


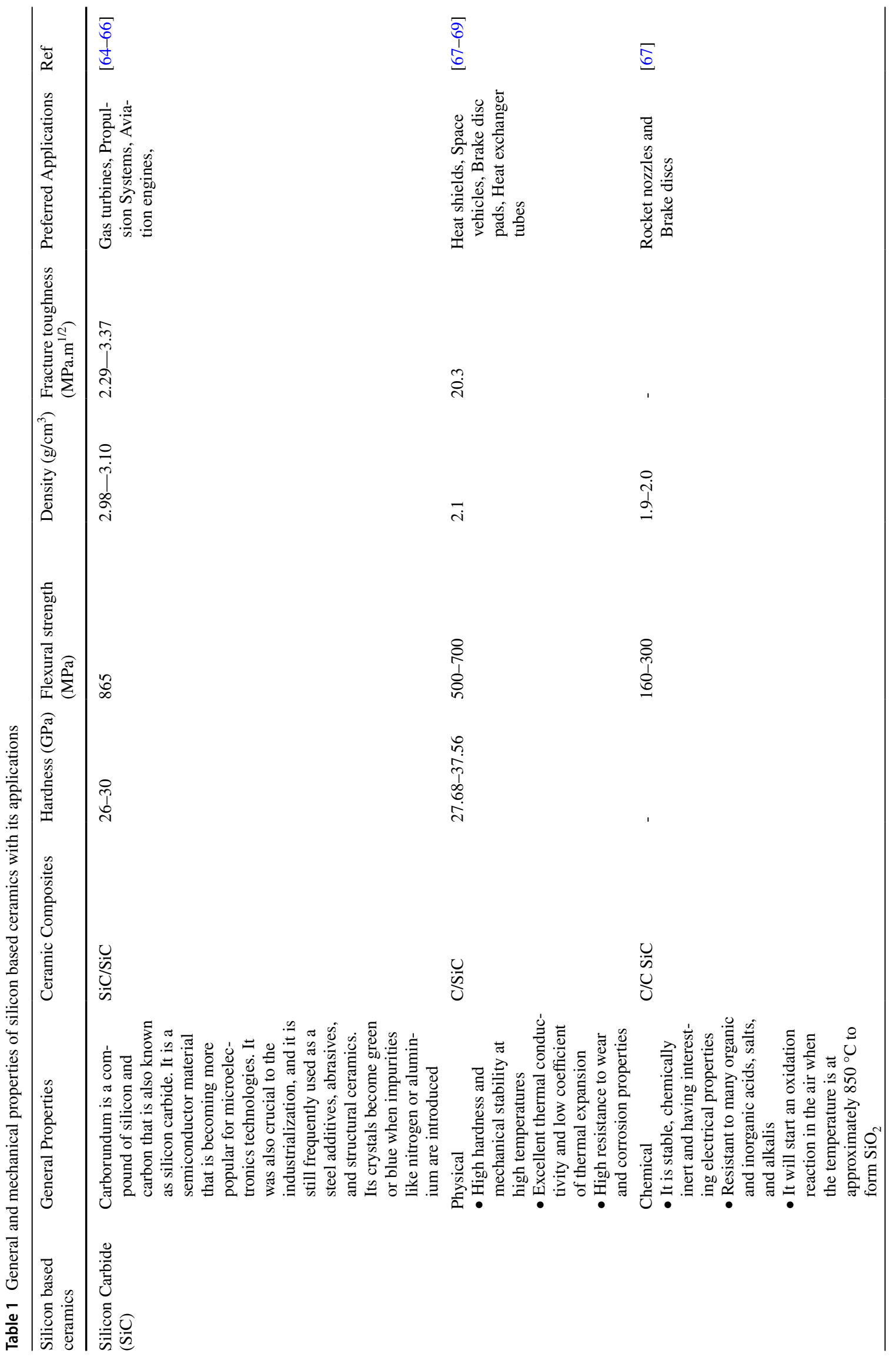




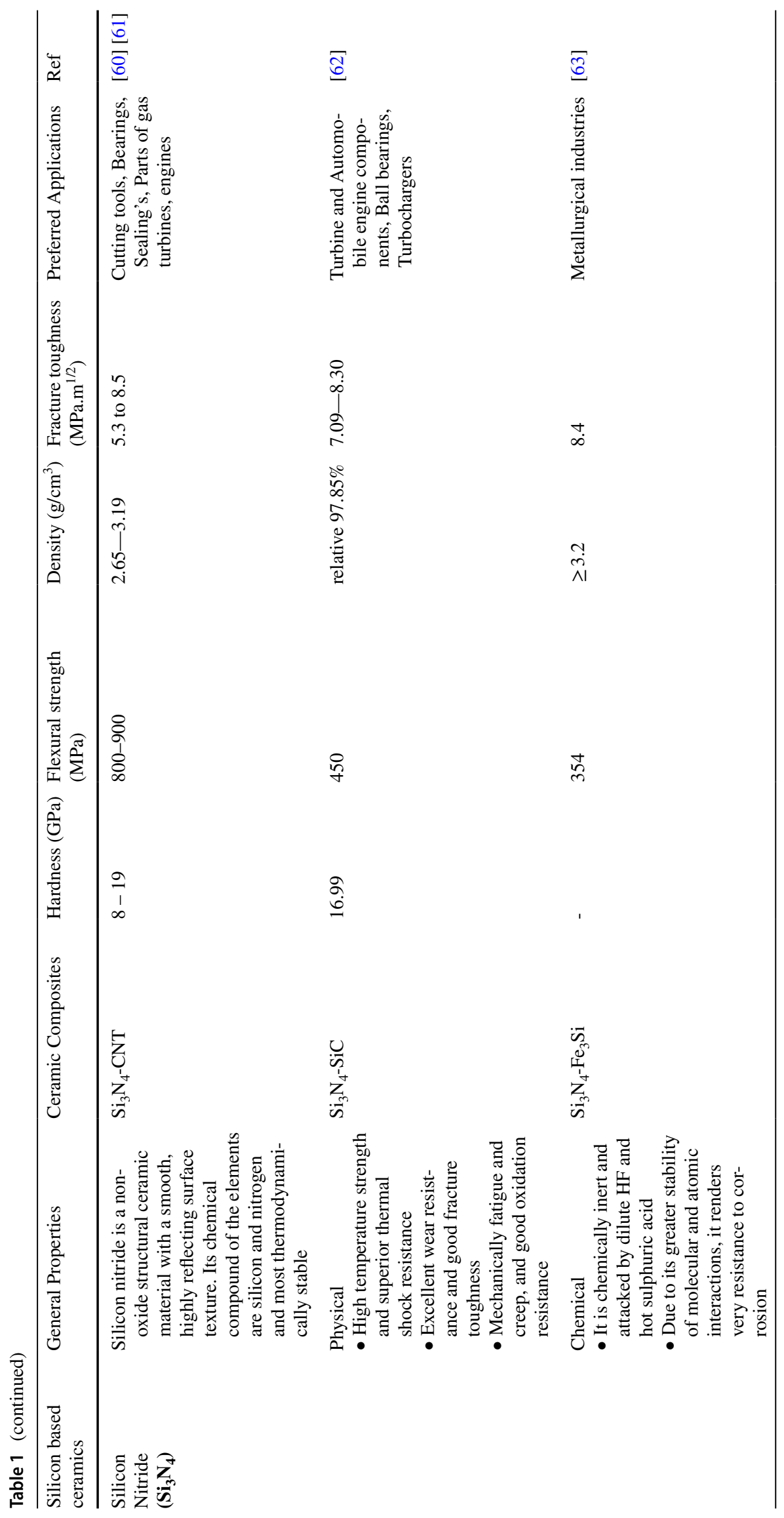




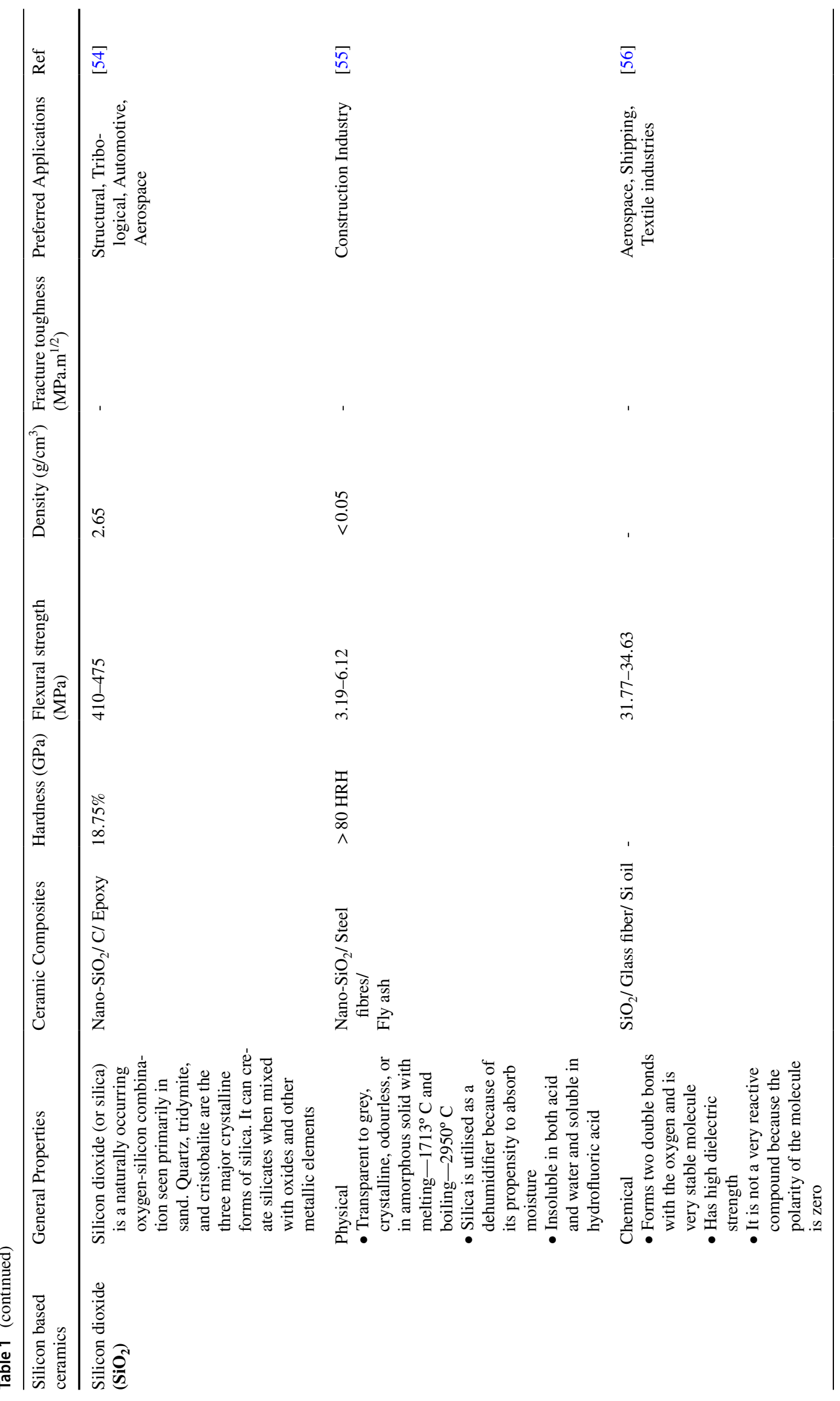


Fig. 6 Classifications of infiltration methods for fabricating CMC

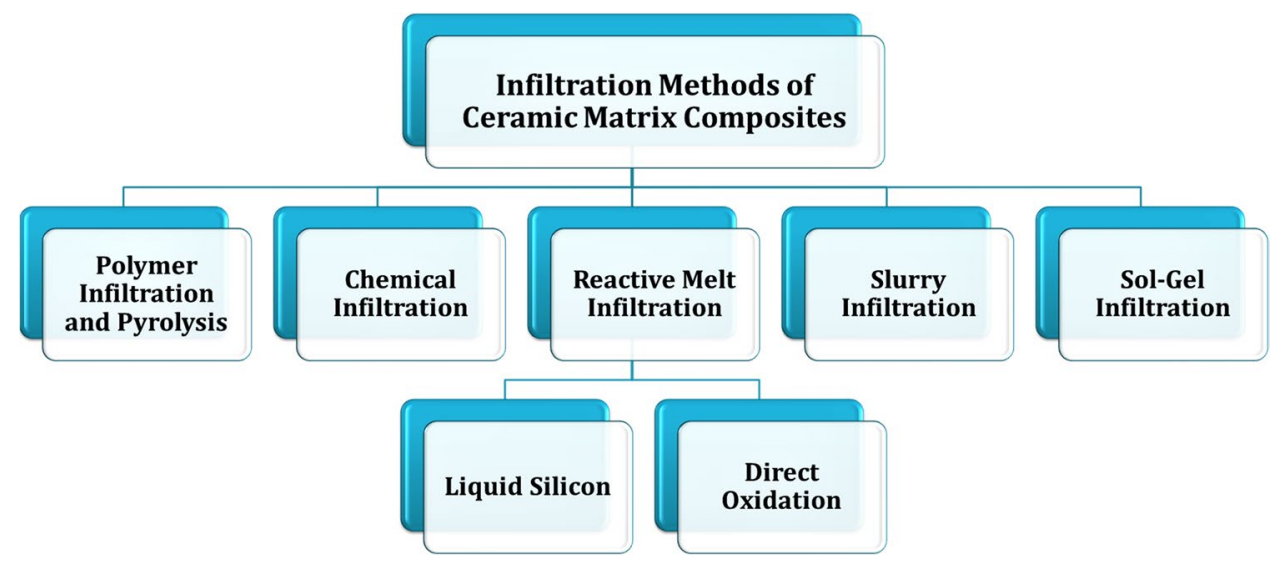

into porous fiber preform followed by decomposition to form CMCs. It is repeated cycling of infiltration followed by pyrolysis. PIP is used for fabricating composites with $\mathrm{SiC}$ or other silicon-based matrices (Silicon Carbon Nitride $(\mathrm{SiCN})$, Silicoboron Carbonitride $(\mathrm{SiBCN})$ and $\mathrm{Si}_{3} \mathrm{~N}_{4}$ ) [70]. $\mathrm{SiC}$ and carbon fibers have been used most frequently in the manufacturing processes of fiber-reinforced CMCs [71]. The pyrolysis process consumes a greater amount of time to produce a proper component with suitable mechanical properties. PIP processing takes less time and costs less than CVI processing for densification. For the desired ceramic, with exact stoichiometric quantities of elements, a polymeric resin can be produced which are suitable choices for a ceramic precursor.

Pyrolysis can result in significant gas evolution. As a result, the gases in the matrix must be allowed to progressively diffuse out. The temperature of the pyrolysis cycle can exceed $1,400{ }^{\circ} \mathrm{C}$. Pyrolysis must take place at a temperature lower than the crystallization temperature of the matrix and the degradation temperature of the reinforcing fiber. Although argon and nitrogen are the most commonly used pyrolysis environment gases, ammonia produces a pure amorphous $\mathrm{Si}_{3} \mathrm{~N}_{4}$ with very little free carbon [72]. Polymerderived $\mathrm{CMCs}$, like $\mathrm{C} / \mathrm{C}$ composites, usually have a broken matrix as well as many tiny pores due to processing. The precursor shrinks around the fibers during pyrolysis, causing cracks. As the ceramic yield rises, fewer gases escape during the pyrolysis process, resulting in fewer pores. Certain modifications are made to the precursors such as Polycarbosilane (PCS)_Allyl-substituted to form AHPCS with 72\% yield, polysiloxane-starfire systems resin with $78 \%$ yield, boron modified AHPCS with $75 \%$ yield, polymer-thysilane added before curing at $320{ }^{\circ} \mathrm{C}$ with $91 \%$ yield [73-75].

The PIP has been used to prepare a multi-walled carbon nanotube which is a reinforced $\mathrm{C}_{f} / \mathrm{SiC}$. The antimony substituted polymer-thysilane was used as a precursor. The ceramic yield of the component was increased with curing after each infiltration procedure [76]. Components produced with the help of this process can be widely used for high-temperature structural materials such as $\mathrm{SiC}_{\mathrm{f}} / \mathrm{SiC}$ composites. They are widely used in gas turbines, aerospace propulsion systems. As the pyrolysis temperature rises, so do the mechanical properties of the composites [77]. Moreover, by pyrolyzing and processing at lower temperatures, fiber degradation and the production of undesirable reaction products at the fiber/matrix contact can be avoided. The tensile strength of amorphous $\mathrm{SiC}$ fibers derived from precursors was reduced by crystallization. The ablation property of components is also important and if the composite's mass loss and linear recession rates were less, the ablation resistance was found to be superior [78]. Figure 7 shows the schematic representation of working process of polymer infiltration and pyrolysis method for CMCs.

The use of particle fillers in the matrix, when mixed with a polymer, reduces shrinkage and hardens the matrix material in the composite, which can control a significant amount of shrinkage. The filler must be $\mu \mathrm{m}$-sized and have the same coefficient of thermal expansion as the polymeric matrix to permeate the bundle. The filler should not be used in excessive quantities, and the slurry should not be injected into the reinforcing fiber. Fiber architecture may have an impact on PIP. The wetting of the fiber bundles is one of the most important aspects. As the precursor contracts around the fiber during pyrolysis, cracks appear [79]. By imposing PIP fabrication procedures in the industrial sectors, may solve many present problems; it provides a method for fabricating CMCs at low temperatures without degrading the fibre while maintaining tight control over the microstructure and composition. Fabrication of desired shapes is possible, allowing CMCs to be utilised more often in the industrial sector. Here in PIP, the different types of reinforcing phases like particulate, fibrous may be used and even net shaped parts can be fabricated. Since there is no free silicon in PIP, therefore no brittle structures can be formed, and a variety of matrices may be constructed using alternative sources of reinforcement other than silicon. 
Fig. 7 Schematic of polymer infiltration and pyrolysis process

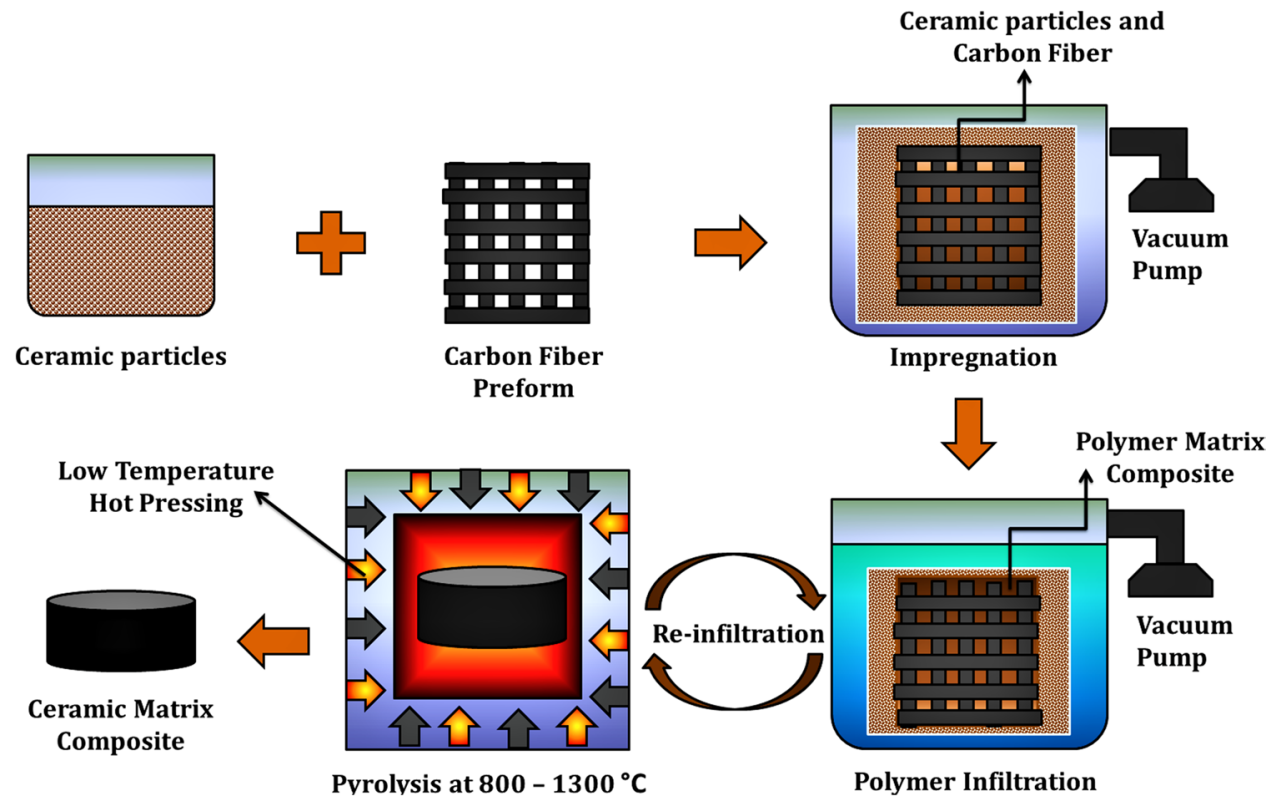

\subsection{Chemical Vapor Infiltration}

CVI is a technique of fabricating ceramic matrix in which reactive gases permeate into an isothermal porous preform comprised of long continual fibres and deposited. The deposited substance is the consequence of a chemical reaction on the outer surface of the fibres. It is similar to CVD, in which deposition forms when the reactive gases react on the outer substrate surface. It is widely used for fabrication of $\mathrm{SiC}$ matrix composites reinforced by $\mathrm{SiC}$ long continuous fibers. The commonly preferred vapor reagents supplied to the preform in a stream of a carrier gases are hydrogen, argon, helium etc. A method directly derived from CVD in which chemicals directly deposit on the surface of the substrate. The CVI process is a specific kind of CVD process [80]. Until now $\mathrm{SiC}$ ceramics were manufactured by processes such as castings, rolling where these processes have resulted in shrinkage and serious whisker damages hence calling the need for the CVI process [81-83]. Manufacturing silicon carbide whiskers reinforced Silicon Carbide matrix $\left(\mathrm{SiC}_{\mathrm{w}} / \mathrm{SiC}\right)$ ceramics by $\mathrm{CVI}$ has been investigated by researchers particularly focusing on the advantages of the process, $\mathrm{SiC}_{\mathrm{w}}$ is ball milled into slurry using Polyvinyl Butyral (PVB) as the binder followed by casting the slurry into the mold and subjecting the specimen to isobaric/isothermal (I-CVI) process. Figure 8 illustrates the flow process of CVI steps used in manufacturing of $\mathrm{SiC}_{\mathrm{w}} / \mathrm{SiC}$, the results of the process show increased volume fraction of $\mathrm{SiC}_{\mathrm{w}}$ and therefore inferring its ability in control of the volume fraction and the porosity of the ceramic, only being limited by the fluidity of the slurry [84].

The $\mathrm{SiC} / \mathrm{SiC}$ used in high-temperature applications such as nuclear reactors require high purity, are typically manufactured by the Forced Chemical Vapor Infiltration process (FCVI). The feasibility of the process is studied by comparing the results obtained from conventional CVI to FCVI [85]. The results obtained display that FCVI is a much faster process in terms of process time, higher deposition rates, lower porosity, and higher uniform densification [86]. Hence larger application of FCVI can provide a path for its application in nuclear reactors. This $\mathrm{C} / \mathrm{SiC}$ has become promising material of choice possessing excellent thermal, mechanical, and ablative properties [87-90]. The deposition channels/pores in $\mathrm{C} / \mathrm{SiC}$ get easily blocked during the infiltration process further giving rise to bottleneck effects and limited densification [91, 92]. Figure 9 depicts the schematic view of working process of CVI method for CMCs.

These issues were tackled using Laser Assisted Chemical Vapor Infiltration (LA-CVI). LA-CVI technique fabricated $\mathrm{C} / \mathrm{SiC}$ by processing the infiltration of the preform by $\mathrm{SiC}$ at $1800{ }^{\circ} \mathrm{C}$ for $2 \mathrm{~h}$ in a vacuum. To generate mass transfer channels, a sapphire laser system was employed to cut holes with a diameter of $0.5 \mathrm{~mm}$. The results showed that $\mathrm{C} /$ $\mathrm{SiC}$ produced by LA-CVI displays properties such as lower porosity, flexural strength, and enhanced density when compared to the conventional CVI process [93]. Gaseous precursors can be manufactured by the pulsed Pressure Chemical Vapor Infiltration (PCVI) process. $\mathrm{C} / \mathrm{SiC}$ manufactured by PCVI under the range of 2-5 kPa displays the ability of the process to manufacture multi-layered interphases with the highest pore filling ability, making it a promising method to manufacture highly tailored ceramics [94]. Because of the low infiltration temperatures, this sort of vapor-based chemical infiltration approach may be utilised to create matrices with excellent purity and little fibre damage. The CVI can provide minimal residual mechanical stresses due 
Fig. 8 Fabrication flow process for $\mathrm{SiC}_{\mathrm{w}} / \mathrm{SiC}$ ceramic composites
Fig. 9 Schematic view of chemical vapor infiltration process
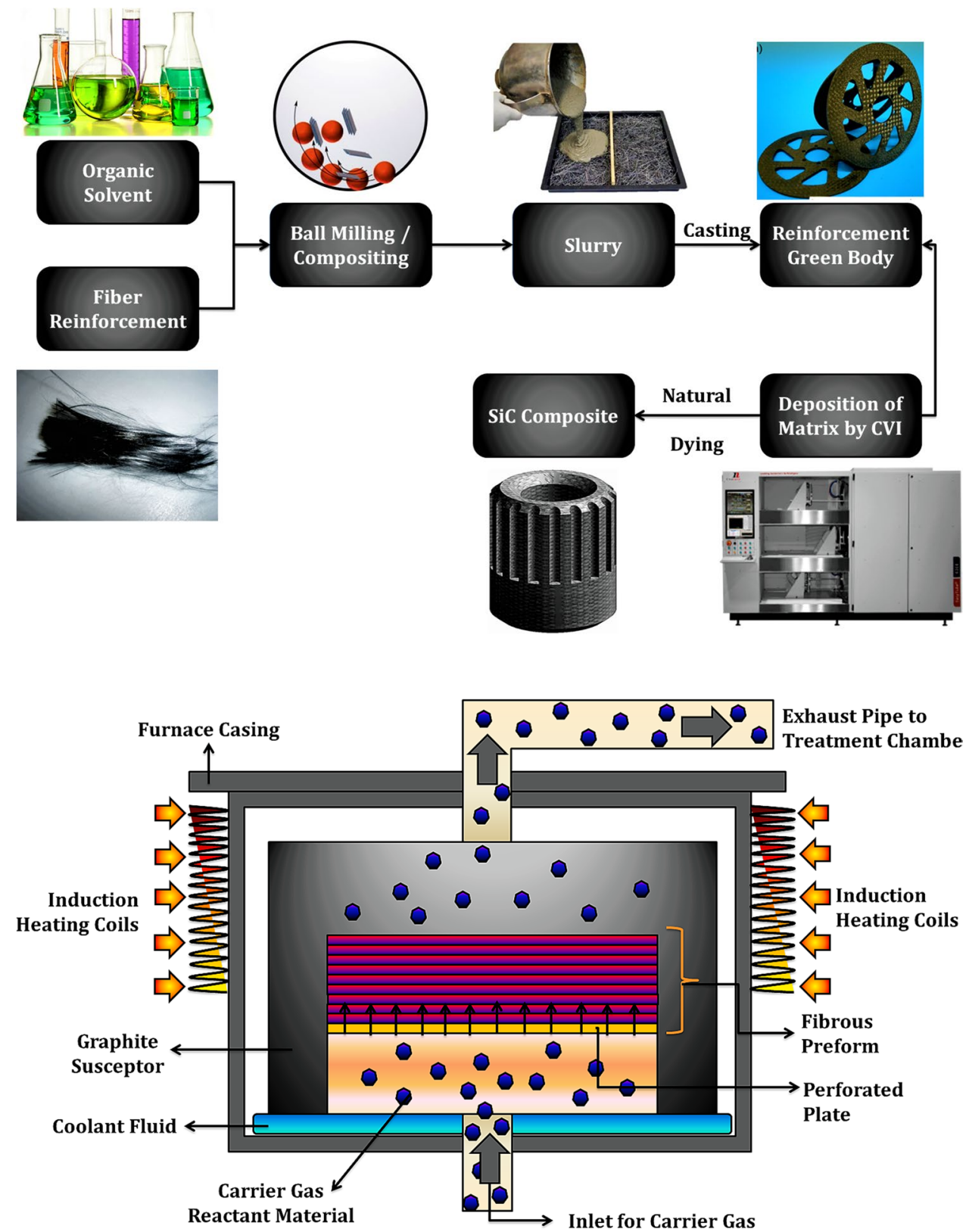

of the low infiltration temperature. This infiltration process has improved mechanical qualities including strength, elongation, toughness, and resisting capacity in thermal shock, creep, and oxidation properties. The CVI has the capacity to construct a variety of ceramic compositions, including $\mathrm{SiC}$, $\mathrm{C}, \mathrm{Si}_{3} \mathrm{~N}_{4}, \mathrm{BN}, \mathrm{B}_{4} \mathrm{C}, \mathrm{ZrC}$, and others, and can give more innovation in manufacturing a variety of high-quality materials.

\subsection{Reactive Melt Infiltration}

Melt infiltration allows for the creation of microstructures that would otherwise be impossible to accomplish by sintering. Before melt penetration, reactive components, for example, can be injected into porous bodies and new phases are produced during infiltration as a result of interactions with the melt. This can be used to manufacture a dense component from a porous moulding body as a replacement to sintering process. The substrate material must have a porosity body with a greater melting point than the invading substance as a requirement. In addition, the melt needs to moisten the substrate material. The porosity body and infiltration substance can then be reheated until the infiltrating material's melting point is reached. Capillary forces pull the melt through the body's pores, entirely filling the pore volume and get a thick component once it cools down. 


\subsubsection{Liquid Silicon Infiltration}

This Liquid Silicon Infiltration (LSI) technique is a type of RMI technique in which the ceramic matrix develops as a result of chemical relationship between the molten material infiltrated into a porous reinforcement phase preform and the substance surrounding the melt, which can be solid or gaseous. Generally $\mathrm{SiC}$ matrix composites are made with this method. The procedure includes infiltrating molten silicon into a carbon microporous preform at a temperature higher than its melting point. The molten silicon wets the carbon preforms surface and the capillary pressure help the melt seep into the porous material. Figure 10 shows the schematic of working process for liquid silicon infiltration process for ceramic composites.

The MI process also known as LSI is an alternative route, where the CMCs are fully densified [95]. This process is widely used to make composite material from the ceramic preform with porosities. The wetting conditions between the solid ceramic and liquid metals are important for performing the MI process. During the phase of infiltration, the weight of the final composite can be monitored. It can be measured before consolidation as well as through the process of this infiltration [96]. For the fabrication of the melt infiltrated CMCs, there developed a variety of processing schemes. Where the one process is the prepreg process and the other one is known as the slurry cast process. The gas turbine engine components are made up of $\mathrm{SiC} / \mathrm{SiC} \mathrm{CMCs}$ that is manufactured through the slurry cast MI process as they have high thermal conductivity, also with higher thermal shock, creep, and oxidation resistance [96]. The melt is inert to the fiber preform in a nonreactive process, so it is not distorted during the infiltration where the furnace uses Radio Frequency (RF) coils to melt the infiltrant and its melt drains upon the preform to make it a dense composite [97].

Along with the addition of $\mathrm{BN}$ interphase to $\mathrm{SiC}$ composite $(\mathrm{SiC} / \mathrm{BN} / \mathrm{SiC})$, the applications can be enhanced and used in higher temperatures [98]. But it is hard to prevent $\mathrm{BN}$ interphase and $\mathrm{SiC}$ fiber from getting oxidized at intermediate temperatures [99]. The laminated Silicon Carbide reinforced Titanium Silicon Carbide $\left(\mathrm{SiC} / \mathrm{Ti}_{3} \mathrm{SiC}_{2}\right)$ can be fabricated by LSI [100]. For $\mathrm{Ti}_{3} \mathrm{SiC}_{2}$ the energy absorbing mechanism which includes delamination, crack deflection, and grain pull-out has also been explored [101, 102]. The laminated ceramics has considerable properties and enhances the impact and damage resistance on the material as they contain multi-scale hierarchical structures [103, 104].

The Carbon reinforced Carbon-Silicon Carbide C/C-SiC is a novel class of high-performance ceramic material with a multiphase matrix composition and internal $\mathrm{SiC}$ layers, which gives it several advantages in the various applications where it can be employed. The LSI technique is used to fabricate this lightweight, thin-walled C/C-SiC. Because of their excellent thermal conductivity and less coefficient of thermal expansion, $\mathrm{C} / \mathrm{C}-\mathrm{SiC}$ possess excellent thermal shock stability and some abrasion resistance [105-107]. The parameters of the carbon preform play a big role in the success of an LSI of SiC creation. To reduce the amount of residual carbon and silicon phases in the LSI reaction result, carbon performs are developed and microstructures are better tailored. MI enables the development of surface morphologies that would be impossible to achieve with sintering alone. As a result of interactions with the melt, new phases
Fig. 10 Schematic view of liquid silicon infiltration process

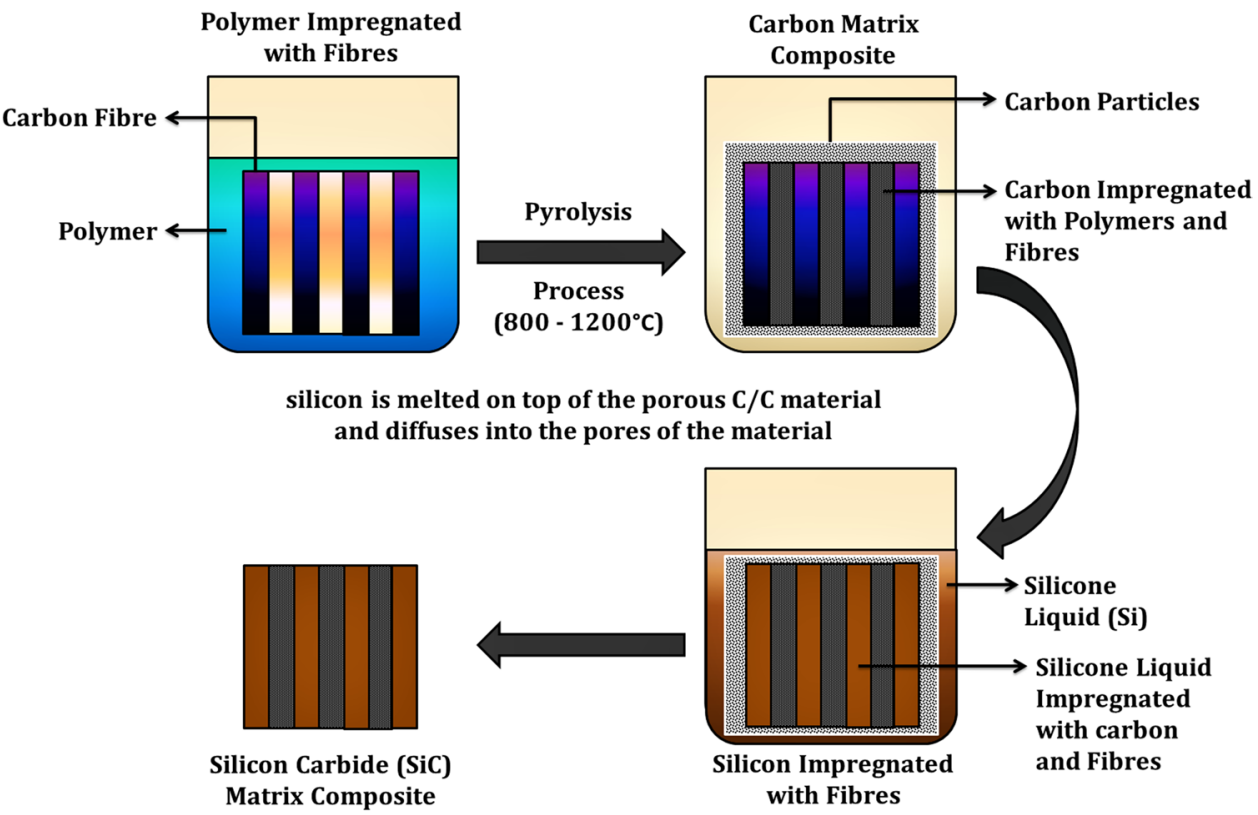


are formed during infiltration. This LSI technique has the capacity to fabricate complex and near net-shape components. During this process, more carbon can be added to porous material and this carbon interacts with the silicon melt, forming additional $\mathrm{SiC}$ and significantly enhancing the hardness and stiffness of the $\mathrm{Si} / \mathrm{SiC}$ material. Stresses can be decreased by adjusting the thermal expansion coefficients of the involved phases to one another. This method may be used to make even material composition and quality gradients and has the potential to satisfy a specific need for the manufacturing of certain ceramics.

\subsubsection{Direct Melt Oxidation}

The interaction of a molten metal with an oxidising gas is the basis of the directed metal oxidation process (e.g. aluminium alloy reacts with air to form $\mathrm{Al}_{2} \mathrm{O}_{3}$. This process is also known as the interaction of metals with dry gases that results in the development of oxides or any other substances on the surfaces; and it is only noticeable at high temperatures. This interaction result extends outwardly from the initial metal pool surface either into available space or into filler at a particular critical temperature range over the metal's melting point. The growth continues until the metal supply is depleted or the reaction front comes into contact with a barrier substance that prevents any further reactions. Figure 11 illustrates the schematic view of direct melt oxidation working process for $\mathrm{CMC}$.

A study performed on $\mathrm{ZrC}-\mathrm{W}$ composites was made by reacting $\mathrm{Zr}_{2} \mathrm{Cu}$ into a Tungsten Carbide (WC) preform at $1200{ }^{\circ} \mathrm{C}$ respectively. The WC substance in the alloy totally interacted with the $\mathrm{Zr}$, and the inclusion of tungsten increased the flexural and fracture toughness properties of the $\mathrm{ZrC}-\mathrm{W}$ composites [108]. Tin oxide $\left(\mathrm{SnO}_{2}\right)$, as a viable contender, has considerable promise for lithium and sodium batteries due to its comparatively large capacities and outstanding stability. A study was conducted on the incorporation of tin oxide nano-particle into CNTs through a melt infiltrating procedure for improving the performance of lithium and sodium ion storing devices. The finding indicates that this composite is capable of producing reversible discharging in these batteries [109]. Similarly, in another study, thick alumina- $\mathrm{TiAl}_{3}$ composites drew a lot of interest due to their superior fracture tolerances and for wear resisting properties [110].

\subsection{Sol - Gel Infiltration}

This Sol-Gel infiltration technique is preferred for making ceramic matrix comprises the matrix from a liquid colloidal suspension of small ceramic particles (sol), which soaks a preform and then solidifies (gel) in formations. When very nanoparticles with radii up to $100 \mathrm{~nm}$ get precipitated in a water or organic solvent, then a colloidal suspension is generated as a result of a chemical process. Because the liquid sols have a low viscosity, they may easily penetrate the preform. Here sols containing organometallic compounds such as metal alkoxide precursor undergo cross-linking process like polymerization at increased temperatures by either the poly-condensation or hydrolysis mechanisms. Then the polymerization turns a sol into a gel, which is a polymer structure that contains liquid and gels may be converted to ceramics at a low temperature, reducing the risk of reinforcing fibre breakage.

The sol-gel method is preferred for attaching Zirconium (Zr) to silica-covered $\mathrm{Al}_{2} \mathrm{O}_{3}$ particles and using phosphatebased monomer as an adhesion booster [111-113]. Wetground pre-sintered Zirconia $\left(\mathrm{ZrO}_{2}\right)$ blocks were sectioned into $0.5 \mathrm{~mm}$ thick discs after being wet-ground into $18 \mathrm{~mm}$ diameter cylinders. Before being immersed in $\mathrm{SiO}_{2}$ solution for five days, the pre-sintered $\mathrm{ZrO}_{2}$ discs are divided into groups. After the immersion period, the $\mathrm{ZrO}_{2}$ discs which are pre-sintered are baked at $100{ }^{\circ} \mathrm{C}$ for a couple of days. The sintered specimens are examined using x-ray diffraction.
Fig. 11 Schematic of working procedure of direct melt oxidation process

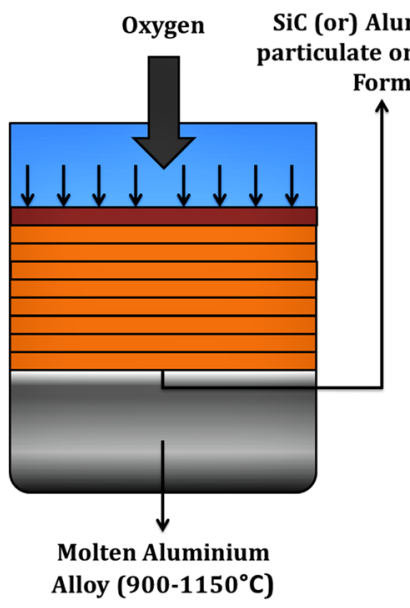

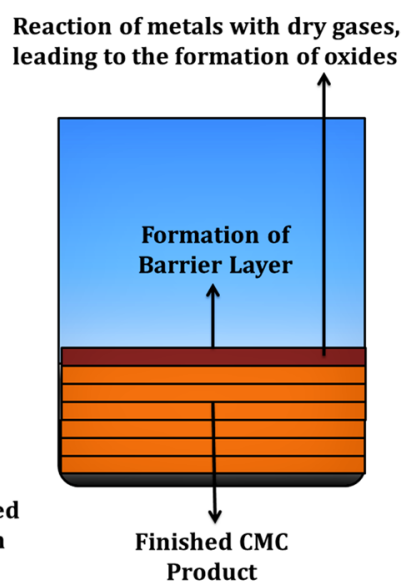


The material's homogeneity was shown to be superior to that of other treatments when employing weibull analysis [114]. $\mathrm{SiO}_{2}$ deposition results in glass/ $\mathrm{ZrO}_{2}$ /glass sandwich layers with graded $\mathrm{ZrO}_{2}$ properties. Furthermore, unlike air abrasion, the sol-gel process does not affect ceramic surfaces [115-117]. Figure 12 shows the schematic view of working process of sol-gel infiltration process for CMC.

Composites of $\mathrm{SiC}$ in a pure $\mathrm{SiO}_{2}$ gel matrix were prepared. Before gelation, SiC fibers or whiskers were mixed with a $\mathrm{SiO}_{2}$ sol. Tetraethyl Orthosilicate (TEOS) was hydrolyzed with $\mathrm{HCl}$ in ethanol to produce $\mathrm{a} \mathrm{SiO}_{2}$ sol with a mole ratio of 1:4:0.5:0.0G of TE0S: water: alcohol: $\mathrm{HCl}$. Sol-gel processing was used to create high purity $\mathrm{ZrO}_{2}$ powder and thin-film applications such as porous membranes for gas filtration, thick-coated layers for corrosion protection. Additionally, the sol-gel technique can be used to create partially stabilized $\mathrm{ZrO}_{2}$ fibers for making $\mathrm{Zr}$ matrix composites with increased mechanical properties [118-121]. A sol-gel technique with metal alkoxides was used to make monoclinic $\mathrm{ZrO}_{2}$ ceramics with a biomorphic structure from jelutong wood, as well as biomorphic $\mathrm{Al}_{2} \mathrm{O}_{3}, \mathrm{TiO}_{2}$, and $\mathrm{ZrO}_{2}$ ceramics from cellulose fiber preforms [122-124].

Fabrication of $\mathrm{Si}_{3} \mathrm{~N}_{4}-\mathrm{SiO}_{2}$ composites by sol-gel together with gel casting has been studied by researchers, the fabrication process includes gel casting of porous $\mathrm{Si}_{3} \mathrm{~N}_{4}$ using acrylamide, followed by $\mathrm{SiO}_{2}$ infiltration in a vacuum, the results from this research showed that with the addition of $\mathrm{SiO}_{2}$, the porosity decreased significantly from $49.3 \%$ to $22 \%$, with a recognizable increase in density from $1.62 \mathrm{~g} /$ $\mathrm{cm} 3$ to $2.18 \mathrm{~g} / \mathrm{cm} 3$, with an increase in flexural strength and dielectric properties and better thermal shock resistance with a decrease in porosity $[125,126]$.

Using sol-gel processing, parts such as heat shields for space shuttles are made using a combination of glass fibers of $\mathrm{Al}_{2} \mathrm{O}_{3}-\mathrm{B}_{2} \mathrm{O}_{3}-\mathrm{SiO}_{2}$ (Nextel 312 fibers) with high-purity
$\mathrm{SiO}_{2}$ fibers. Unlike the powder or slurry precursors, sol-gel has many advantages such as less fiber damage, good chemical composition flexibility, low densification at temperatures, and improvement in oxidation behavior of infiltrated components $[121,127]$. The sol-gel method is simple, economical and efficient method to produce high quality coverage and has the capacity of sintering at low temperatures, between $200-600{ }^{\circ} \mathrm{C}$. Sol-gel spin coating technique was used to create colloid-based highly reflective coatings on glass substrates, consisting of alternating layers of quarter wave thick high and low refractive index components. The bonding regions were enhanced with the increasing concentration of $\mathrm{SiO}_{2}$, the sharp angles surrounding the pores were also softened, and some interconnected pores might be separated into distinct pores after the sol-gel infiltration and sintering process. This kind of microstructure made it difficult for the cracks to propagate, so the flexural strength and fracture toughness were distinctly improved.

\subsection{Slurry Infiltration}

In Slurry Infiltration (SI) process, the reinforcing fibres are allowed to flow through slurry that penetrates the pores structure of the reinforcing phase in the infiltration process. The capillary effect is the primary force behind infiltration, however vacuum or pressure can help speed up the process. These infiltrating fibres are coiled onto a mandrel during the lay-up process. After that, it's dried, sliced, and placed out and they are chopped and placed up on a tooling after drying (mold). Then, at a high temperature and increased pressure, hot pressing process (sintering, densification) is done, which improves the dispersion of the ceramic material between the particles absorbed into the fibres structure. The particles clump together, resulting in a dense composite with reduced porosity level. Figure 13 represents the schematic
Fig. 12 Schematic of working process of sol-gel infiltration method

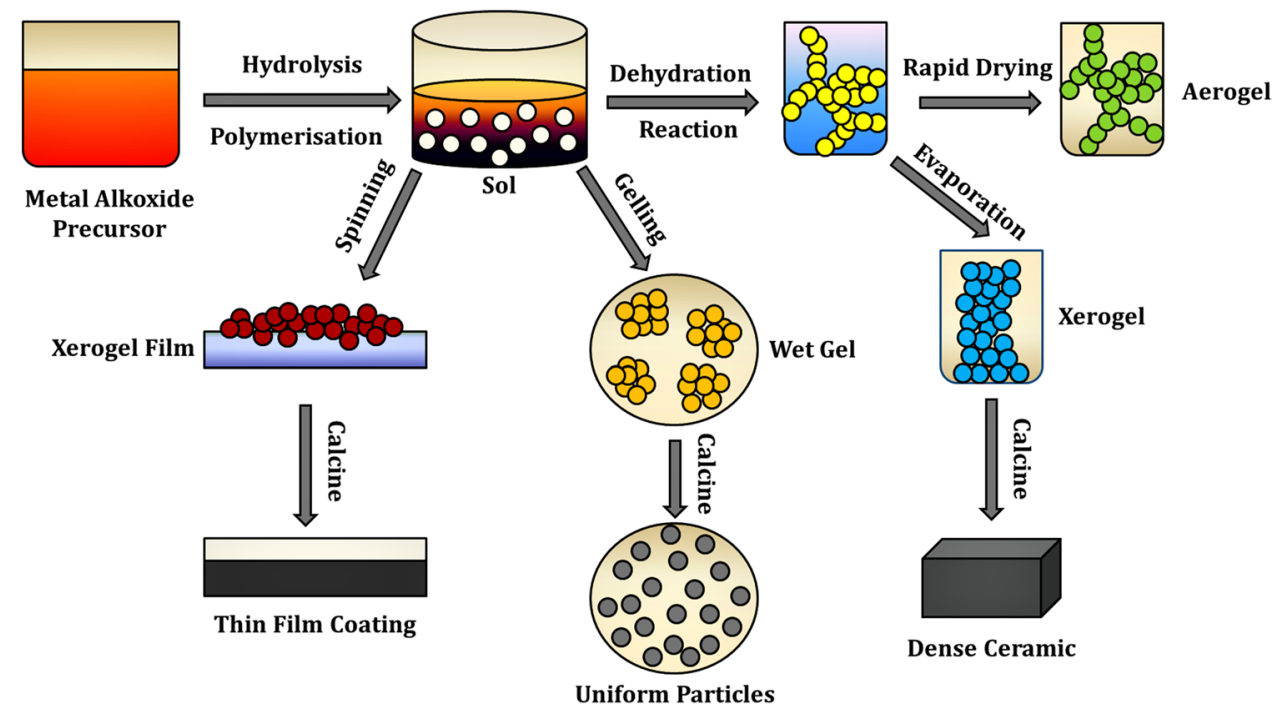


Fig. 13 Schematic of working process of slurry infiltration method

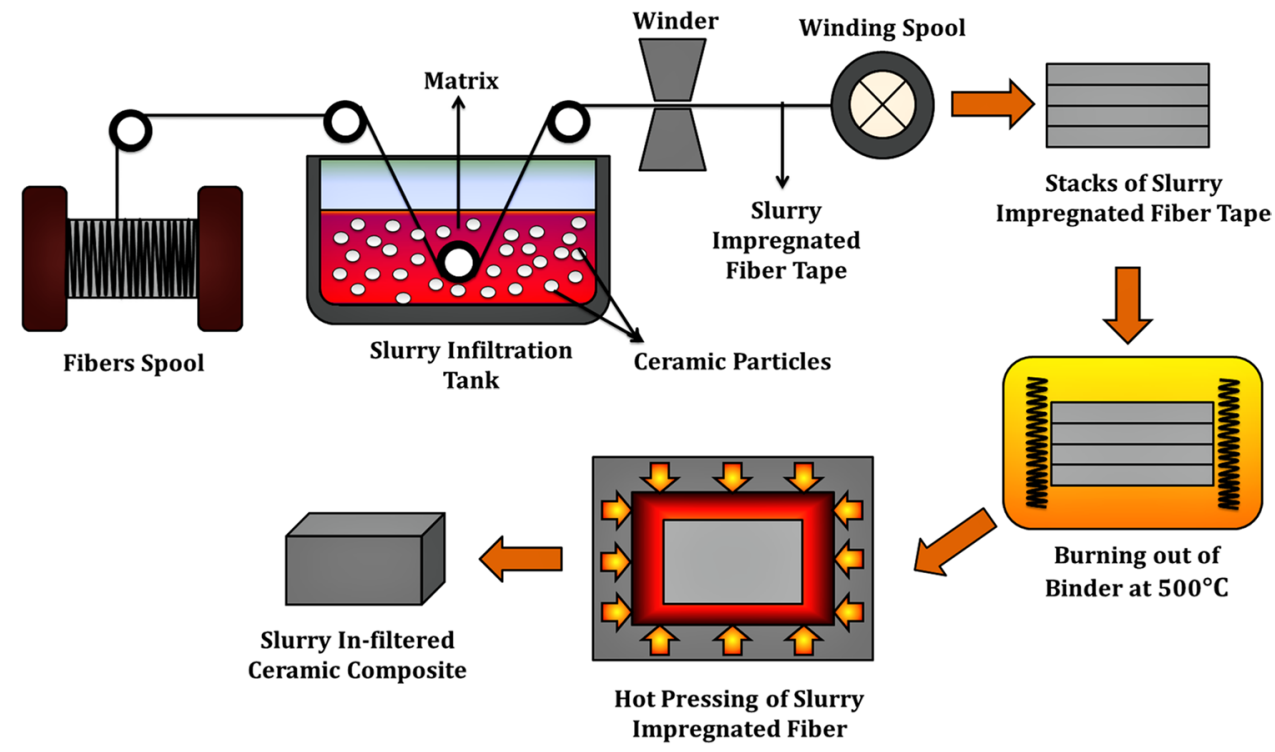

view of working process of slurry infiltration process of ceramic composites.

Continuous fiber-reinforced CMCs have long been recognized as promising materials usually finding their applications in brake disks, heat exchangers, aero-engines, and fusion reactors because of their high toughness, low density, thermal \& chemical stability [128-131]. $\mathrm{C}_{\mathrm{f}} / \mathrm{SiC}$ has been the chosen composite because of its low cost and better thermal stability, usually being processed by complex processes such as liquid-vapor infiltration and hot pressing [132-135]. The effects of the addition of $\mathrm{SiC}$ particles to $2 \mathrm{D}-\mathrm{C}_{\mathrm{f}} / \mathrm{SiC}$ as filler which is then fabricated by SI process have been studied [136]. The former composite was then manufactured by using $2 \mathrm{D}$ woven $\mathrm{C}$ fiber which was used to prepare fiber preform, followed by an infiltration of $\mathrm{SiC}$ filler, enhancement of infiltration efficiency was assured by using a vacuum pump. The properties of the composite obtained were compared and analysed for two different pyrolysis temperatures $\left(800 \& 1100{ }^{\circ} \mathrm{C}\right)$. The results showed that the amount of $\mathrm{SiC}$ had a significant effect on physical and mechanical properties of the composite, lower $\left(800{ }^{\circ} \mathrm{C}\right)$ pyrolysis temperature exhibit lowest failure stress whereas, with an increase in the temperature $\left(1100{ }^{\circ} \mathrm{C}\right)$, the composite exhibits failure stress two times higher with an increase in interfacial bonding [137].

Surface tension, viscosity, and volatility were considered as factors in the choice of solvent [139]. For a better dispersion of the slurry, the solvent must have low surface tension and low viscosity, as well as a higher viscosity to convey the slurry particles and a lower vapor pressure to avoid solvent vaporization. When the slurry no longer absorbs into the pores, the surplus slurry can be brushed off the material's surface. The microstructure and ablation behavior of $\mathrm{Ti}_{3} \mathrm{SiC}_{2}$ modified $\mathrm{C} / \mathrm{SiC}$ composites manufactured using a combined
SI and LSI process was investigated. The manufacturing process of $\mathrm{C} / \mathrm{SiC}-\mathrm{TiC}-\mathrm{C}$ composites is performed by infiltrating porous $\mathrm{C} / \mathrm{SiC}$ composites with $\mathrm{TiC} / \mathrm{C}$ slurry and later using a vacuum freeze drier, they are dried [138]. Then the slurry is made using by dissolving TiC particles (1-2 m, 60 wt $\%$ ) with graphite powders $(5 \mathrm{~m}, 6 \mathrm{wt} \%)$ in deionized water and later ball milling it for $24 \mathrm{~h}$. Then, the infiltration of molten silicon of $\mathrm{C} / \mathrm{SiC}-\mathrm{TiC}-\mathrm{C}$ composites at a temperature of $15,000{ }^{\circ} \mathrm{C}$ for $30 \mathrm{~min}$ under vacuum was processed. The internal bundle pores of the $\mathrm{C} / \mathrm{SiC}$ composite are filled with TiC-C particles after SI.

Various SI alterations result in various implications and changes in material properties for the processes such as precursor and pyrolysis for $\mathrm{SiC}_{\mathrm{f}} / \mathrm{SiC}$ composites. Corresponding to a relative density of $68 \%$, the density of the $\mathrm{SiC}_{\mathrm{f}} / \mathrm{SiC}$ filler green body was $2.20 \mathrm{~g} / \mathrm{cm}^{3}[140]$. The infiltration of bulk graphite blocks is performed using the SI slurry process to make graphite composites such as $\mathrm{SiC}$ and $\mathrm{Si}_{3} \mathrm{~N}_{4}$ reinforcements; it's effective by increasing the wear resistance by morphological changes by increasing porosity of bulk graphite. These characteristics are advantageous to parts such as piston rings, sealing rings, bearings, electrodes, crucibles, extrusion guides, and moulds [141]. The SI manufacturing method is comparable to the sol-gel infiltration process; however, because of the increased solid content, SI generates a denser structure with less shrinkage. This SI infiltration process is basically driven by the capillary forces. One of the main advantages of this SI infiltration technique is its low porosity rate and good mechanical properties. However, the high pressure applied to the reinforcing fibres may cause damage, and the hot pressing step necessitates highly expensive equipment; in addition, as compared to other infiltration techniques, simple and compact pieces are manufactured. Figure 14 depicts the various combined 
Fig. 14 Combined infiltration process of ceramic composites
Slurry Infiltration + Polymer Infiltration

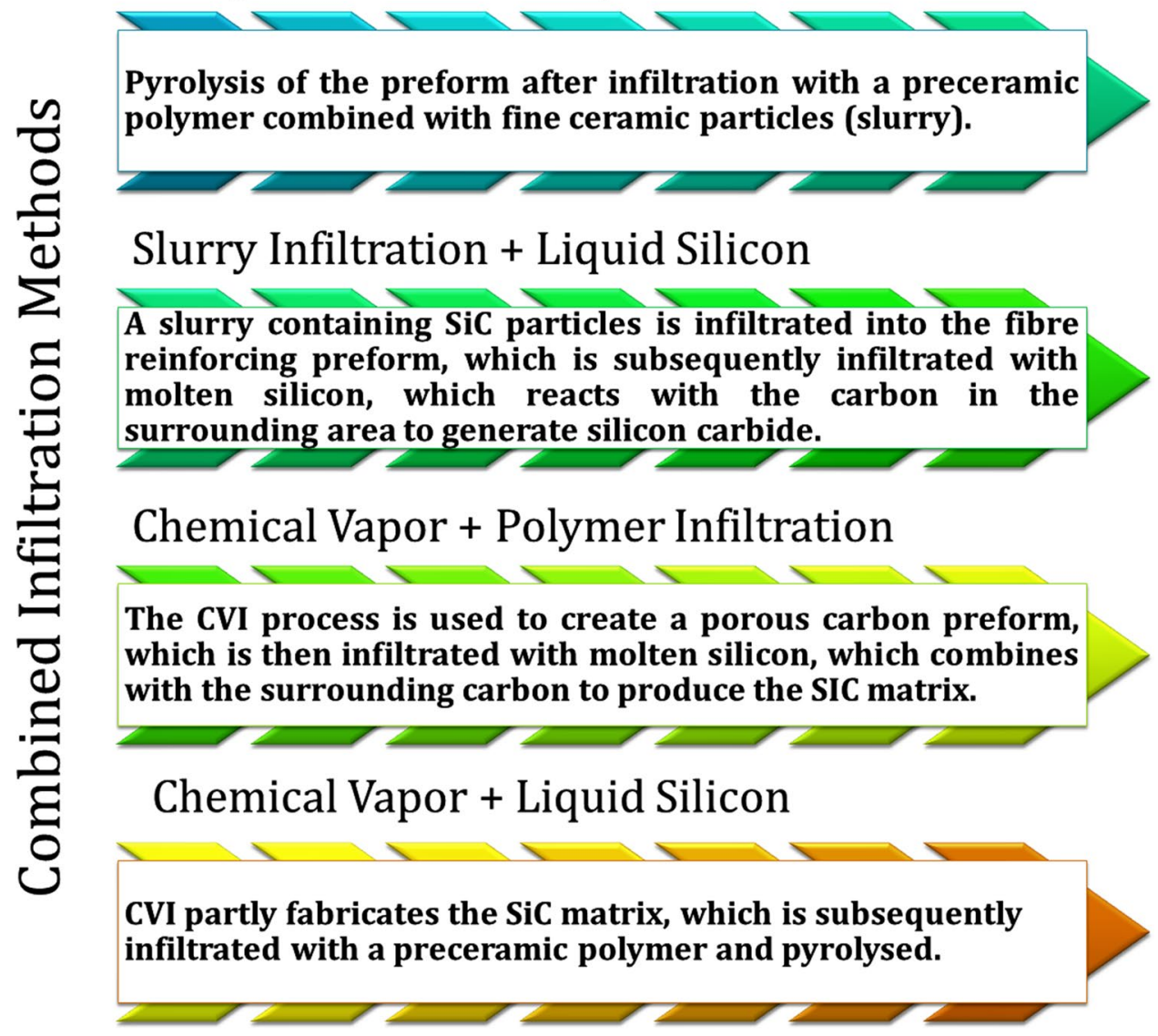

infiltration process of CMCs. Table 2 shows the summary of various infiltration techniques of CMCs.

\section{Applications of Si-Based Ceramic Composites}

They can personalize and reduce their negative features while allowing beneficial properties to coexist in the same component. The following are the engineering applications of Si-based ceramics: Fig. 15 resembles the CMCs in various fields of applications.

\subsection{Automotive}

In sectors such as aircrafts, missiles, automotive and others, the demand for lower density and high-strength materials is growing in replacing conventional higher density metal alloys. Emerging materials such as $\mathrm{C}_{\mathrm{f}} / \mathrm{SiC}$ are replacing metal alloys due to their lower density, higher melting point, higher hardness, chemically inert,superior oxidative and erosive resistance $[142,143]$. Both $\mathrm{C} / \mathrm{C}-\mathrm{SiC}$ and $\mathrm{C}_{\mathrm{f}} /$ $\mathrm{SiC}$ composites have been identified as potential material for the utilisation of braking discs owing to its outstanding friction qualities, which include a higher frictional coefficient, strong abrasive resistance, and a slight reduction in friction coefficient during moist situations [144, 145]. The usage of carbon-fiber-reinforced with ceramic composites in common automobile parts such as brake discs, valves, spark plugs, etc. is increased in large numbers in recent years because of its higher load stability [146]. Moreover, Ceramic Matrix Nano Composites (CMNCs) are used to make materials stoves, nozzle assembly, energy conversion systems, thermal engines, and gas turbines [147, 148]. C/SiC composite brake discs are approved and commercially used in premium automobiles due to their enhanced properties compared to other similar materials. They are manufactured using the LSI technique [149].

\subsection{Aerospace}

The $\mathrm{C} / \mathrm{C}-\mathrm{ZrB}_{2}-\mathrm{SiC}$ composite have prompted the concern for aeronautical engineers owing to its improved properties such as lower density, higher-temperature strength, lower coefficient of thermal expansions, good thermal conduction, and great thermal shock protection. However, the oxidizing and ablation resisting property of $\mathrm{C} / \mathrm{C}$ composites can be enhanced, as carbon may be rapidly oxidised at temperature 


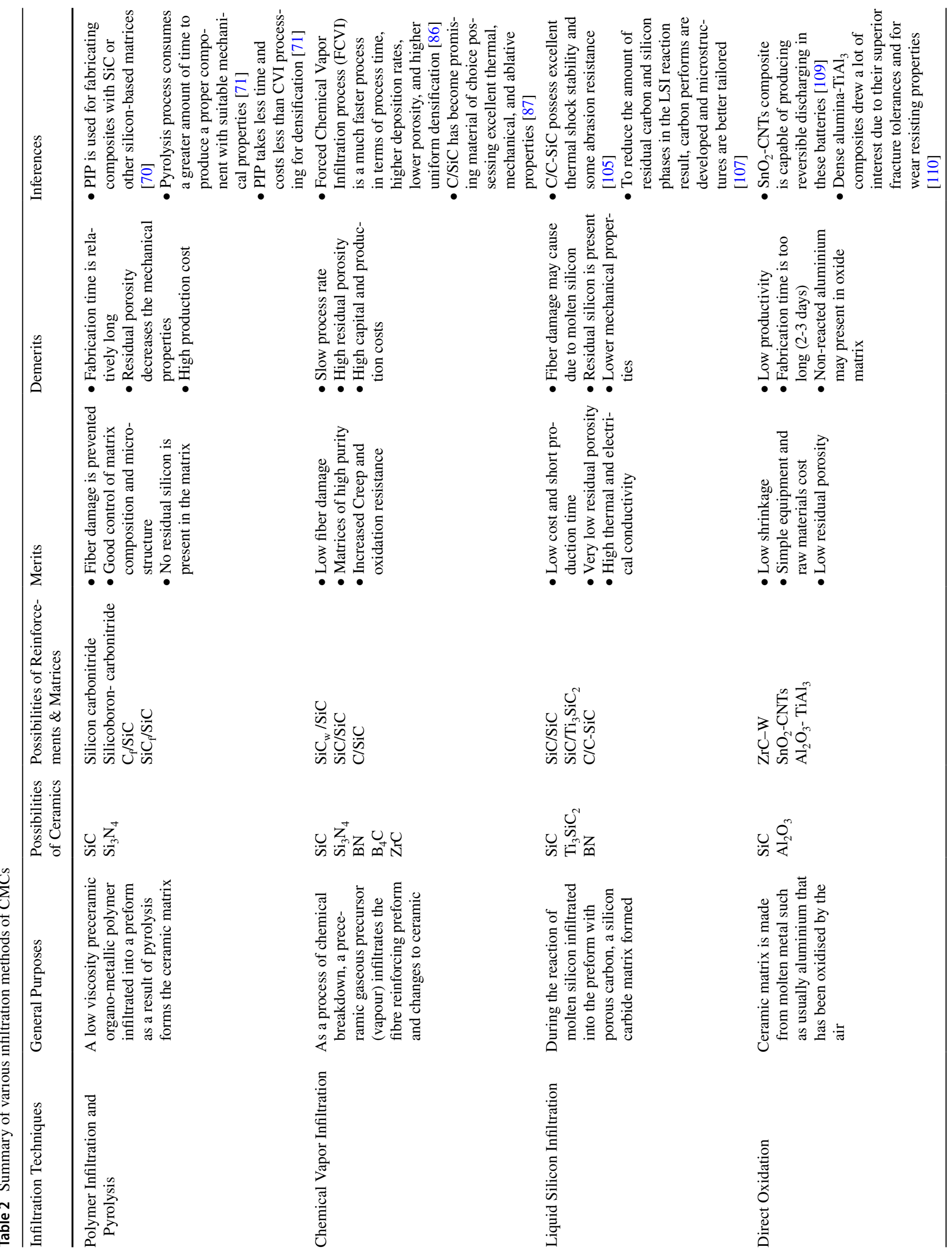




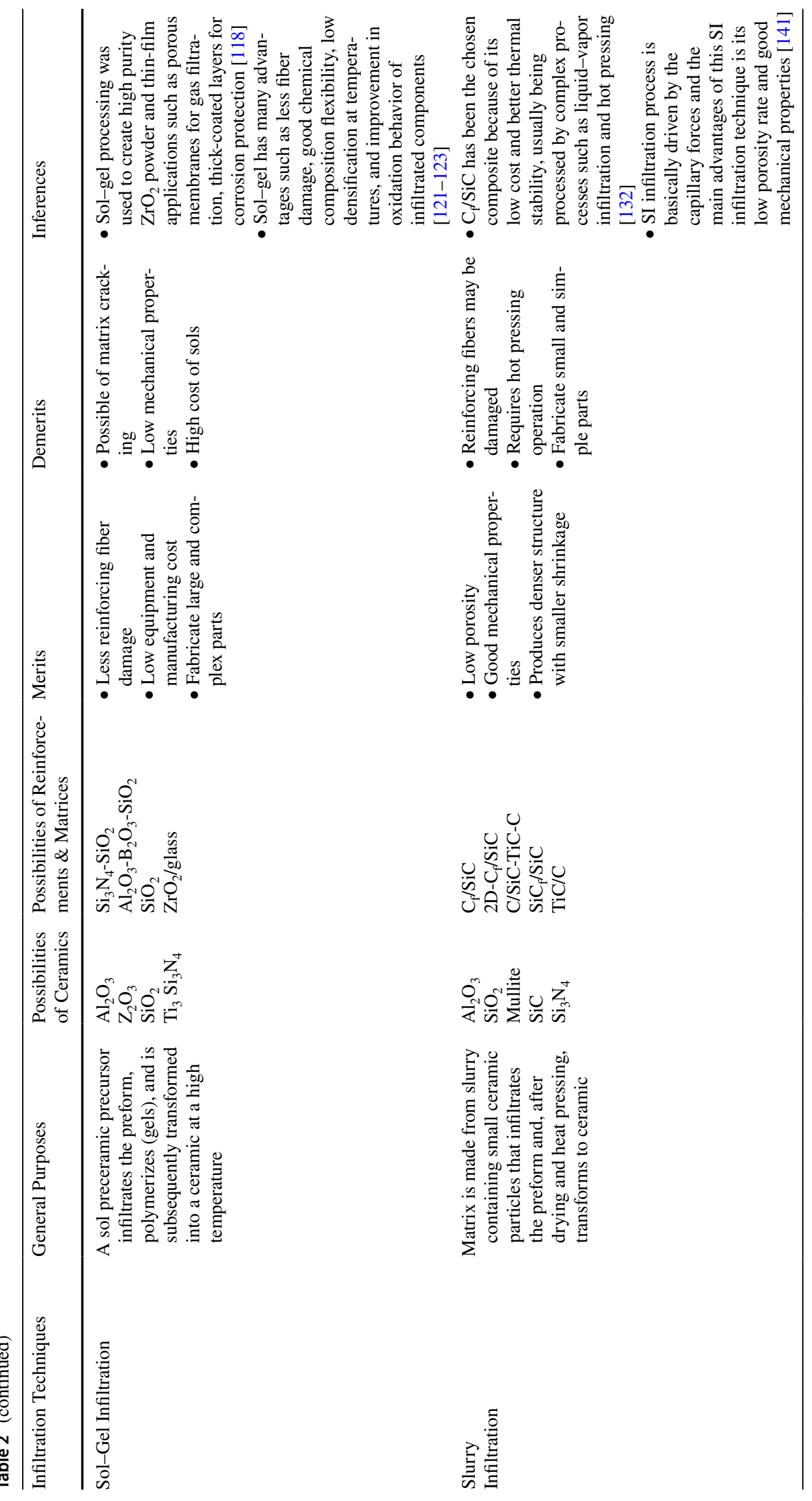


Fig. 15 Applications of CMC in various fields of applications

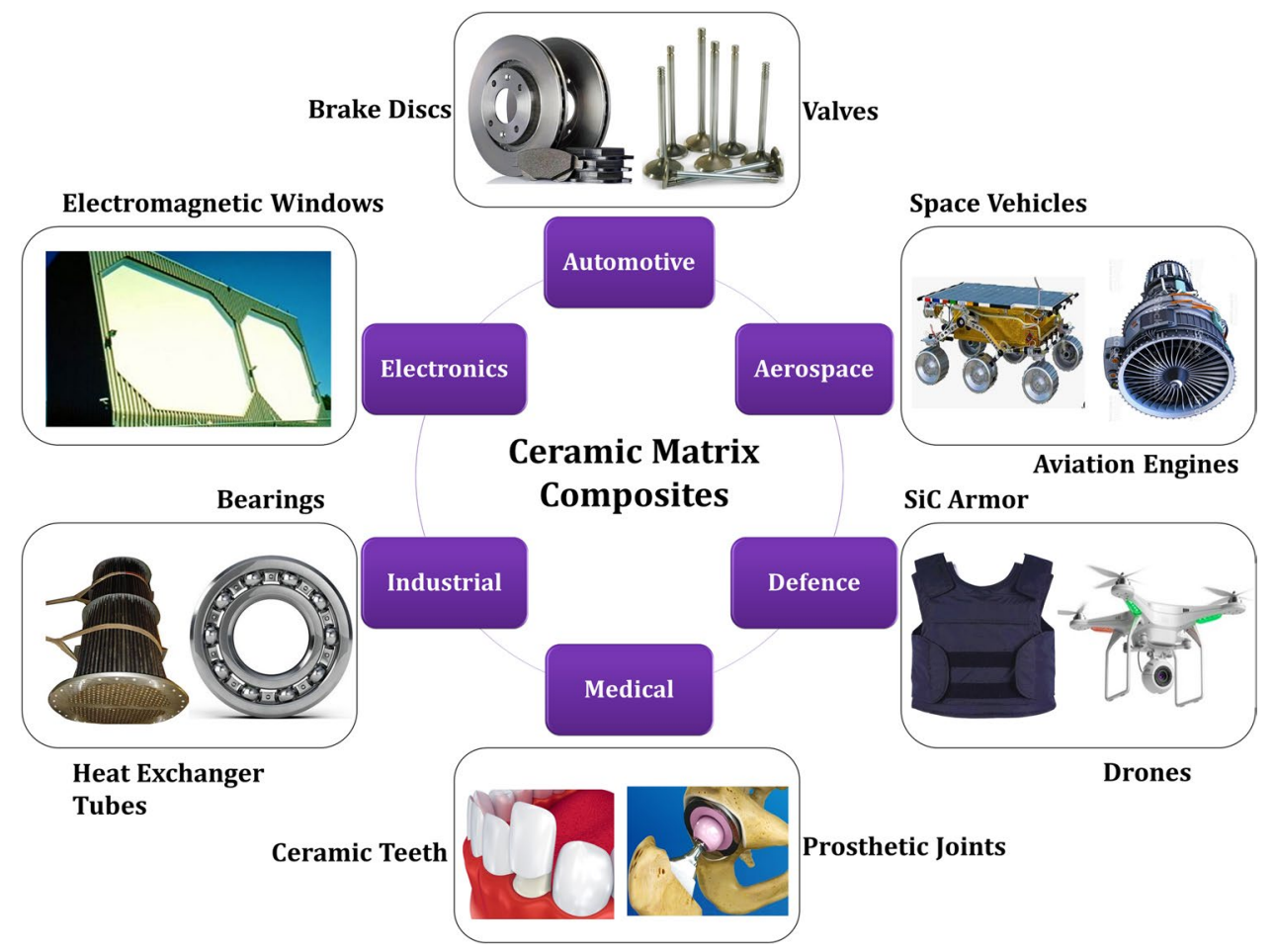

above $450{ }^{\circ} \mathrm{C}$ under oxygenated circumstances, limiting its employment in aeronautical industries [150]. A composite material made up of $\mathrm{SiC}$ reinforcing fibres and $\mathrm{SiC}$ matrices are termed as $\mathrm{SiC}_{\mathrm{f}} / \mathrm{SiC}$. These fibres absorb fracturing energy, due to its higher fracture toughness than monolith ceramics. These composites are now being explored for structural purposes in the aircraft industry and aviation sectors [151-155]. This SiBCN ceramic offers greater thermostability, oxidative resistance, chemical resistant, and creeping resistance than other materials. As a result, it is projected to be exploited as a temperature resisting structural material in the aerospace sectors [156]. Due to low density and good wear corrosion, Silicon Carbide-Aluminium Metal Matrix Composites (Al-SiC MMC) is used to make a variety of aerospace industrial parts. Moreover, the fibers of these materials are used as reinforcing material to make fuselage skins which have properties such as ultimate tensile strength and high yield stress [157].

\subsection{Medical}

The laminated $\mathrm{SiC} / \mathrm{TiSi}_{2}$ and $\mathrm{SiC} / \mathrm{Ti}_{3} \mathrm{SiC}_{2}$ ceramics are great instances of biologically produced substances and materials because they have the adaptability to give particular anisotropy qualities such as strength properties, durability, and stiffness, as well as impact and damaging resistance [158]. Owing to its optical characteristics, dental ceramics such as zirconia and silica resemble real teeth in appearances. Other properties of these ceramics, such as strength and chemical resistance, allowed these materials to be manufactured promptly for dental usage, in order to fulfil the growing need for aesthetics and longevity. A zirconia infiltrated with silica gel improves in two directions such as structural uniformity and resin cemented adhesion. This type of infiltration procedure is straightforward to carry out and control in a prosthetic laboratories [101, 159]. Siloxane is a silicon-based organic-inorganic layer is used in various medical applications. They have essential properties such as chemical stability and inertness, low toxicity, biocompatibility which are important to medicinal and its industrial applications [115].

\subsection{Industrial}

$\mathrm{SiC}$ with porous structure is a type of tailored ceramic substance that has attracted to a wide range of high-temperature engineering application fields. Due to its minimal density, strong heat resistivity, reduced thermal conductivity, and excellent mechanical qualities at extreme temperatures this porous ceramic also preferred in metallurgical field and chemical industries [160-164]. Due to its considerable importance in high temperature applications, this siliconbased ceramics such as $\mathrm{SiC}$ and $\mathrm{Si}_{3} \mathrm{~N}_{4}$ are being explored significantly. Among the non-oxide ceramics, these $\mathrm{SiC}$ and $\mathrm{Si}_{3} \mathrm{~N}_{4}$ ceramics have the best oxidation resistance properties [165]. Si-SiC composites are chosen for ceramic brake pads and furnace components due to their excellent thermomechanical characteristics. Among these composites, $\mathrm{ZrB}_{2}$ has received a lot of attention due to its higher melting 
ranges, toughness, thermal and chemical stability [166]. Carbon linked carbon-fiber composites are a type of C/C composites with a minimal density and higher porosity structure. They were used as thermal protection in vacuuming and inert-gas furnaces which can withstand temperature up to $2800{ }^{\circ} \mathrm{C}$ [167]. Industrial applications include the chemical sector, aluminum manufacture, oil and gas production, and solar cell manufacturing. The SiC-based flow reactors and heat exchangers, industrial pump seals and bearings [168].

\subsection{Military}

Carbon fibre coupled with $\mathrm{ZrC}-\mathrm{SiC}$ composites is recommended for high temperature applications including supersonic vehicles and sharper surfaces in aircrafts. These composites have outstanding features such as fracture toughness, thermal shock absorption, and possess good mechanical characteristics under higher temperatures $[169,170]$. These C/C-SiC and $\mathrm{SiC} / \mathrm{SiC}$ composites are extensively used as functional materials in the aeronautical and aviation industrial sectors due to their higher thermal prevention, enhanced propulsive systems, and other properties such as higher fracture toughness, strength at higher temperatures, reduced density, superior thermal conduction, and oxidative resistance [171, 172].Various ceramics are used to fabricate or manufacture different parts especially ceramics such as $\mathrm{Si}_{3} \mathrm{~N}_{4}, \mathrm{Al}_{2} \mathrm{O}_{3}$, and $\mathrm{SiC}$ parts such as ballistic-resistant exterior tiling for planes, helicopters, and drones, supplanted metal-based armor plates for body armor are fabricated. Among the ceramics mentioned $\mathrm{Al}_{2} \mathrm{O}_{3}$ is used in most parts because of its hardness, modulus of elasticity, refractoriness, and low cost [173].

\subsection{Electronics}

Electronic ceramics account for a significant portion of the advanced ceramics market. For the creation of electrical and electronic circuits, multilayer ceramics such as multi-layered capacitors, multi-layered packages and substrates, and other ceramic electrical components such as PTC resistors, IBL capacitors, PZT ceramics, and dielectric resonators are employed [174]. Due to its outstanding mechanical qualities, strong thermal shock protection, and erosive resistance, $\mathrm{Si}_{3} \mathrm{~N}_{4}$ ceramic is a prospective for tail rotors and photovoltaic systems. These ceramics are also potential material for electromagnetic windows which are nearly transparent to electromagnetic radiation in the frequency ranges and employed in modern systems $[175,176]$. Likewise, the composite boron nitride combines with $\mathrm{SiC} / \mathrm{SiC}-\mathrm{Si}$ are a suitable substance for both electronics field and photonic products, along with higher temperature activities [177]. $\mathrm{SiCN}$ has significant concern due to its ability to combine the characteristics of both $\mathrm{SiC}$ and $\mathrm{Si}_{3} \mathrm{~N}_{4}$ substances. This
$\mathrm{SiCN}$ is a higher temperature resisting material that may be used for a variety of purposes, including Radio Frequency Identification (RFID) shielding which act as a conducting barrier that entirely encloses the device to prevent from environmental disturbances [178-180]. Table 3 resembles the summary of fields of applications of different infiltration process with its flexural strength of ceramic composites. Table 4 resembles the summary of fields of applications of combined infiltration techniques with its flexural strength of ceramic composites.

\section{Future Scope of Si-based Ceramics}

Ceramic matrix composites are likely to see increased demand from the aerospace, defense, automotive, energy, and power end-use industries, as well as their ability to withstand high temperatures and have remarkable mechanical qualities. Product type, end-user industry, and geography are the various segments observed in CMC's market, and its by-product type market is segmented by $\mathrm{C} / \mathrm{SiC} \mathrm{CMCs,}$ $\mathrm{C} / \mathrm{C}$ CMCs, Oxide/Oxide CMCs, $\mathrm{SiC} / \mathrm{SiC}$ ceramic matrix. Automotive, aerospace, defence, energy and power, electrical and electronics and other user industries are segmented by industry. $\mathrm{SiC}$ is well known for its numerous benefits in a variety of sectors, including the biological field. The full potential of this material has yet to be realized, owing to the presence of a high degree of flaws. Despite its wide bandgap, high thermal conductivity, and strong breakdown electric field, when employed in traditional power devices, its performance fails to meet the acceptable limitations at high temperatures due to flaws.

As a result, understanding these faults is critical for furthering their application in the biomedical industry, as they are employed in the development of biomedical devices that go into every region of the body, such as membranes, bio micro electro mechanical systems, stents, drug delivery, biosensors, and so on. The best alternatives for metallic alloys are $\mathrm{SiC} / \mathrm{SiC} \mathrm{CMCs,} \mathrm{which} \mathrm{are} \mathrm{typically} \mathrm{employed} \mathrm{in}$ gas turbines. The revenue shares of silicon-based ceramic composites in the year 2020 is shown in Fig. 16 because of its remarkable oxidation and radiation resistance qualities, $\mathrm{SiC} / \mathrm{SiC} \mathrm{CMCs}$ have seen increased use in the energy and power industries in recent years. For high-temperature structural applications, $\mathrm{Cf} / \mathrm{SiC}$ is considered the most promising material. Large-scale $\mathrm{Cf} / \mathrm{SiC}$ composite components with complicated geometries are often difficult to manufacture, necessitating the use of appropriate joining procedures to link them to themselves or other materials. Despite the transitory impact of COVID-19, the demand for $\mathrm{SiC} / \mathrm{SiC}$ matrix composites is expected to dominate the CMCs market throughout the forecast period due to rising investments in the energy and power sector. 


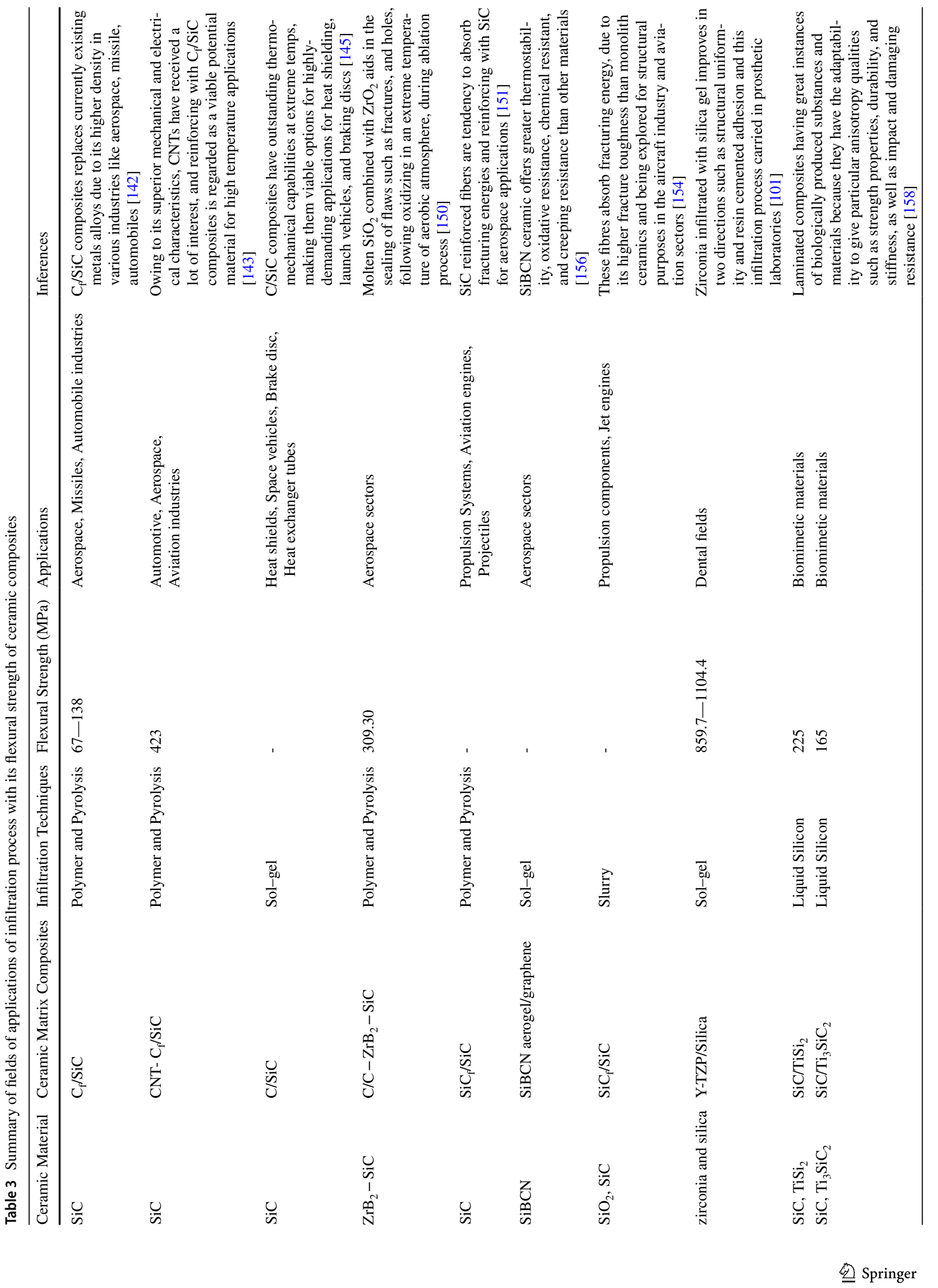




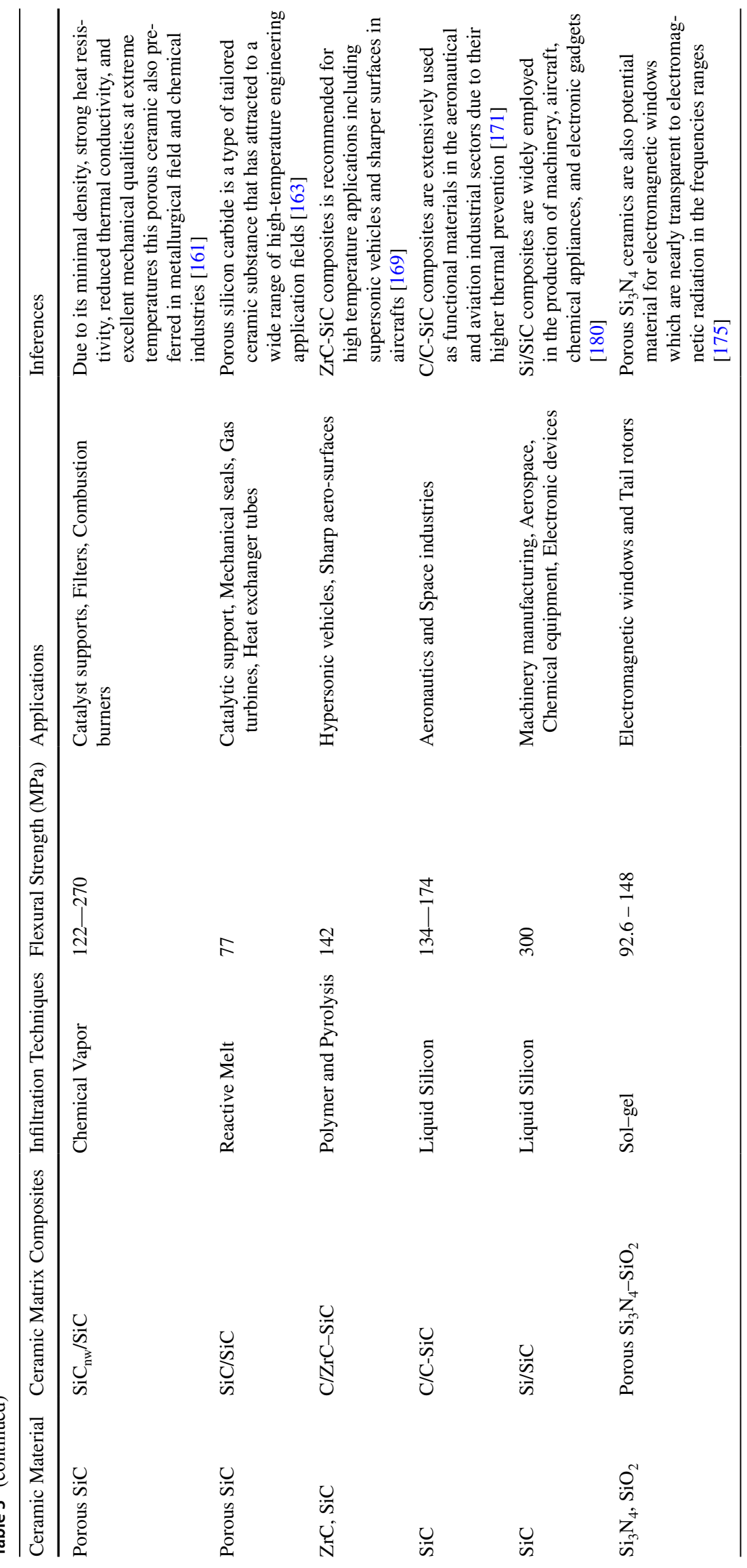




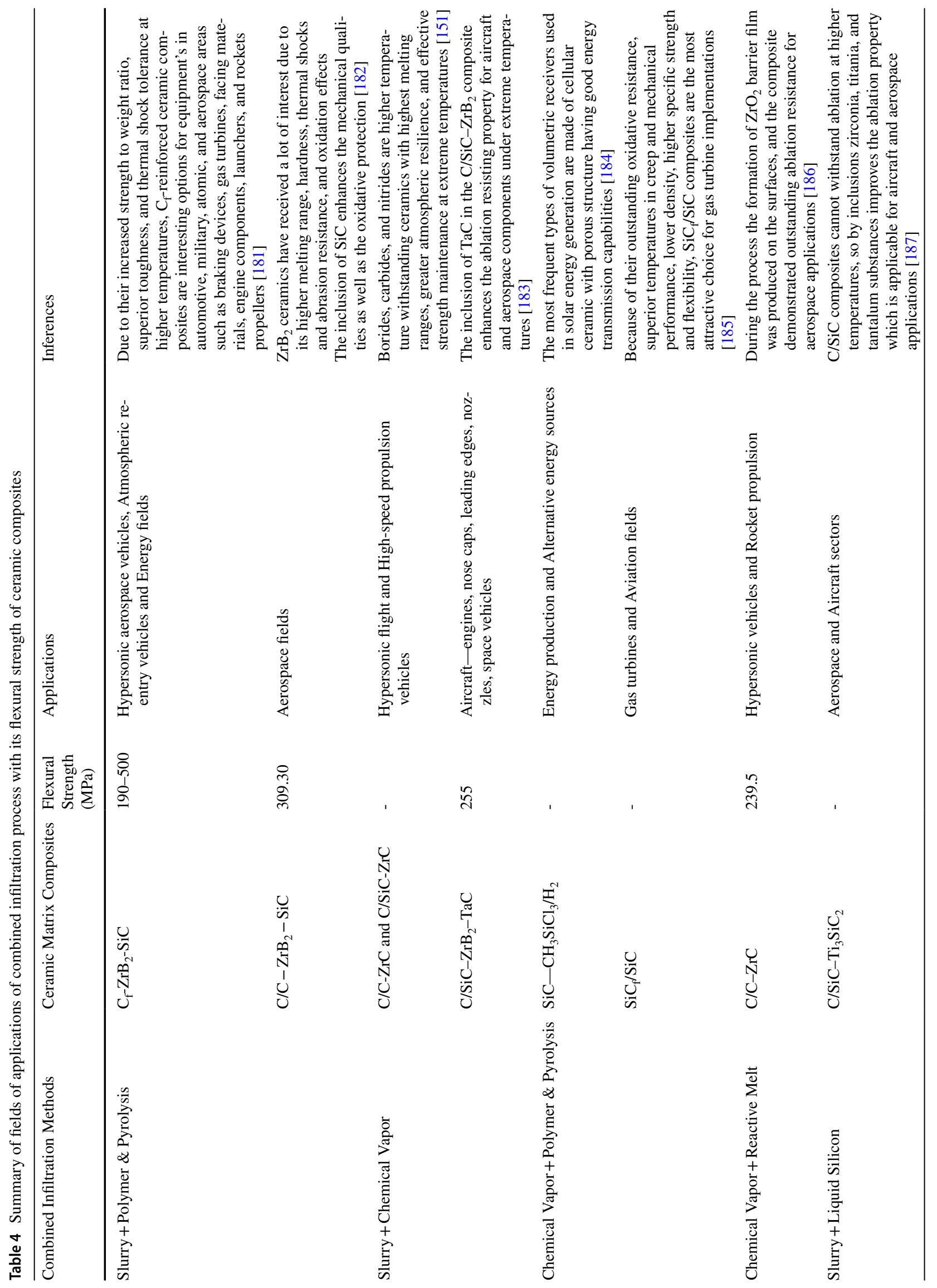




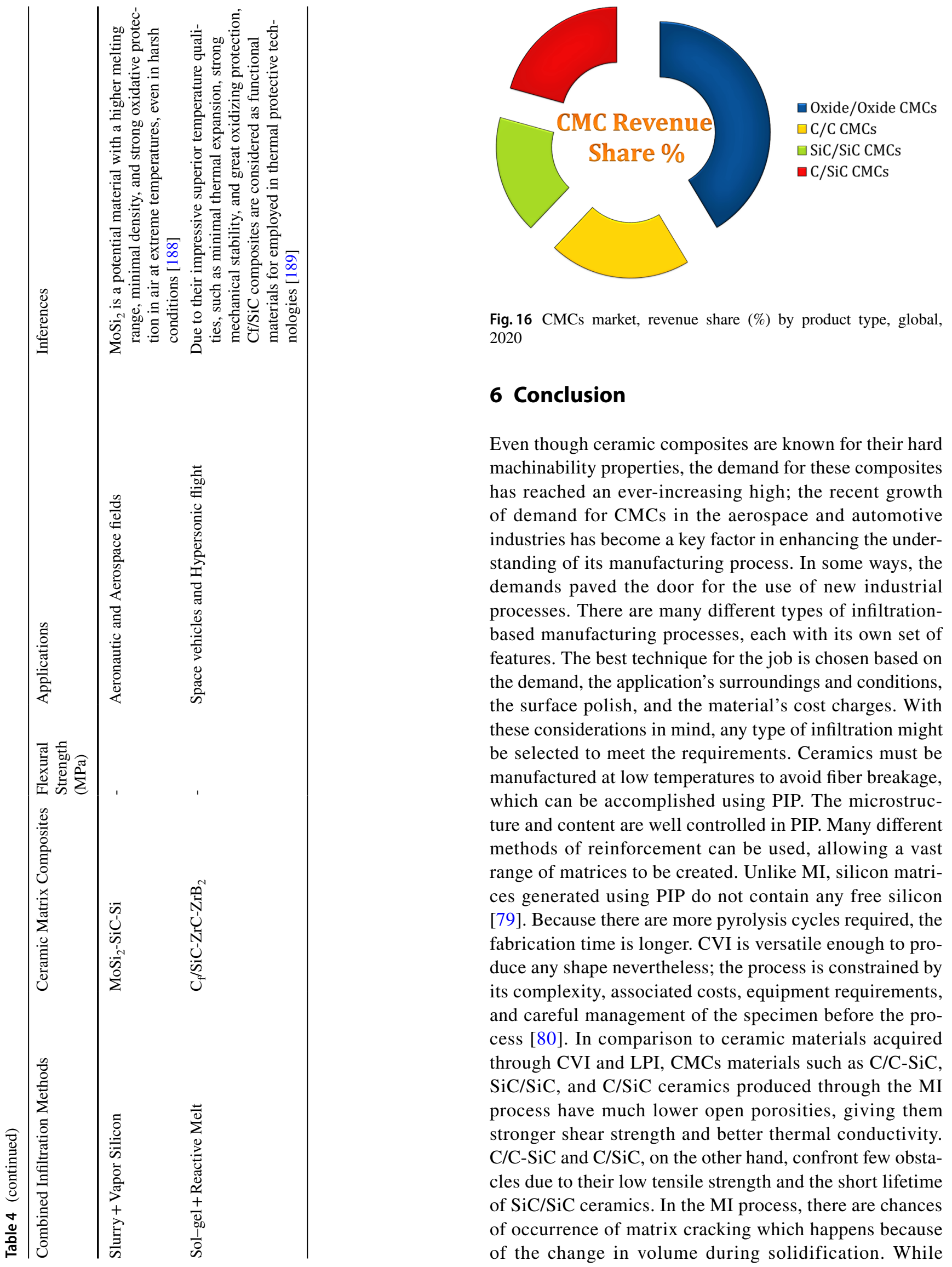


performing SI, the composite will have uniform fiber/ matrix microstructures along with good mechanical properties like high strength and toughness are achieved. As a result of this technique, low porosity of the ceramic material is achieved [190]. The sol-gel process is a remarkable process for manufacturing CMCs at low temperatures that reduces fiber damage, but it lacks certain characteristics such as manufacturing composites with large shrinkages, which causes matrix cracking, and the composites manufactured by this process have lower mechanical properties than their counterparts [191, 192]. Silicon-based CMC's has applications in fields such as automobile, aerospace, aeronautical, marine, and many other industries, It produces promising results in their respective fields. Siliconbased CMC's has a high temperature, resistance to corrosion, strength retention, stress rupture, and high corrosion resistance. Ceramic components display high brittleness with high hardness values. Such a critical component must be fabricated using proper methods such as infiltration techniques. Much research has been conducted using these techniques to study ceramic components. Popular and efficient infiltration techniques like SI, sol-gel and MI were discussed and their various features were outlined, thus providing insights in understanding the established work. Compared to powder or slurry precursor's sol-gel route is advantageous due to lower densification temperatures. Despite all these fabrication processes, the selection and application of the manufacturing process ultimately depend on the process application and the constraints in the working environment. In sectors such as aircrafts, missiles, automotive, and others, the demand for lower density and high-strength materials is growing to replacing conventional higher density metal alloys. Emerging materials such as $\mathrm{C}_{\mathrm{f}} / \mathrm{SiC}$ are replacing metal alloys due to their lower density, higher melting point, and higher hardness, chemically inert, superior oxidative and erosive resistance.

Acknowledgements We thankfully acknowledge the inevitable contribution of Nikhil R, Kousik K M, Suthershan K and Naresh Viswaraj M during data collection through literature survey.

Authors' contributions Conceptualization: Dr. Radhika N; Methodology: Dr. Radhika N; Formal analysis and investigation: Dr. Radhika N, Sathish M; Writing_original draft preparation: Dr. Radhika N, Sathish M; Writing_-review and editing: Dr. Radhika N, Sathish M; Tabulation and pictorial representations: Sathish M; and Supervision: Dr. Radhika N.

Funding No funding information to be declared for this research.

Data Availability The raw data required to reproduce these findings are included within the manuscript, no additional raw data is required to reproduce the results.

\section{Declarations}

Ethics approval This is a review based on peer-reviewed data published on reputed journals, which requires no ethical approval.

Consent to participate Informed consent was obtained from all individual participants included in the study.

Consent for publication Hereby declare our consent for the publication of identifiable details, which can include photograph(s) and/or details within the text ("Manuscript") to be published in the above Journal and Article. I confirm that I have seen and been given the opportunity to read both the Material and the Article (as attached) to be published by Springer.

Disclosure of potential conflicts of interest The authors have no conflicts of interest to declare that are relevant to the content of this article.

Research involving Human Participants and/or Animals Not Applicable.

Informed consent Not Applicable.

Competing interests The authors have no competing interests to declare that are relevant to the content of this article.

\section{References}

1. Nallusamy T, Vijayakumar S (2021) Reinforcements, Manufacturing Techniques, and Respective Property Changes of $\mathrm{Al}_{2} \mathrm{O}_{3} /$ SiC Based Composites: A Review. SILICON. https://doi.org/10. 1007/s12633-021-01108-1

2. Rao BS, Rao TB (2021) Mechanical and Tribological Properties of 3D printed Al-Si alloys and composites: a Review. SILICON. https://doi.org/10.1007/s12633-021-01340-9

3. Radhika N, Sasikumar J, Jojith R (2021) Effect of Grain Modifier on Mechanical and Tribological Properties of Al-Si Alloy and Composite. SILICON 13:841-855. https://doi.org/10.1007/ s12633-020-00476-4

4. Radhika N, Andrew Jefferson J (2019) Studies on Mechanical and Abrasive Wear Properties of Cu-Ni-Si/Si ${ }_{3} \mathrm{~N}_{4}$ Functionally Graded Composite. SILICON 11:627-641. https://doi.org/10. 1007/s12633-018-9957-2

5. Dmitri Kopeliovich (2018) Advances in manufacture of ceramic matrix composites by infiltration techniques. Adv Ceram Mat Comp 93-119. https://doi.org/10.1016/B978-0-08-102166-8. 00005-0

6. Jianfeng Zhang, Mohsin Hassan Saeed, Suyan Li (2018) Recent progress in development of high-performance tungsten carbidebased composites: Synthesis, characterization, and potential applications. Adv Ceram Mat Comp 307-329. https://doi.org/ 10.1016/B978-0-08-102166-8.00013-X

7. Xia Z, Li L (2014) Understanding interfaces and mechanical properties of ceramic matrix composites. Adv Ceram Mat Comp 267-285. https://doi.org/10.1533/9780857098825.2.267

8. Davidge RW (1969) Mechanical properties of ceramic materials. Contemp Phys 10(2):105-124. https://doi.org/10.1080/00107 516908220103

9. Bianchi V, Goursat P, Sinkler W, Monthioux M, Ménessier E (1997) Carbon-fiber-reinforced (YMAS) glass-CMCs I preparation, structure and fracture strength. J Eur Ceram Soc 17(12):1485-1500. https://doi.org/10.1016/S0955-2219(97) 00004-6 
10. Watari K (2001) High thermal conductivity non-oxide ceramics. J Ceram Soc Japan 109(1265):7-16. https://doi.org/10.2109/ jcersj.109.S7

11. Dressler W, Riedel R (1997) Progress in silicon-based non-oxide structural ceramics. Int J Refract Hard Met 15(1-3):13-47. https://doi.org/10.1016/S0263-4368(96)00046-7

12. Radhika N, Praveen G, Gautham Rathan P (2014) Study of wear behaviour of $\mathrm{Al} /$ ( $\mathrm{Al} 2 \mathrm{O} 3 \mathrm{p}$ and $\mathrm{SiCp}$ ) hybrid metal matrix composites. Malaysian J Sci 33(1):78-88. https://doi.org/10.22452/ mjs.vol33no1.9

13. Radhika N, Balaji TV, Palaniappan S (2015) Studies on mechanical properties and tribological behaviour of LM 25/SiC/Al2O3 composites. Int J Eng Sci Technol 10(2):149-159

14. Boschetto F, Adachi T, Horiguchi S, Fainozzi D, Parmigiani F, Marin E, Zhu W, McEntire BJ, Yamamoto T, Kanamura N, Mazda O (2018) Monitoring metabolic reactions in staphylococcus epidermidis exposed to silicon nitride using in situ time-lapse raman spectroscopy. J Biomed Opt 23(5):056002. https://doi.org/ 10.1117/1.JBO.23.5.056002

15. Jannotti P, Subhash G, Zheng J, Halls V (2017) Measurement of microscale residual stresses in multi-phase ceramic composites using raman spectroscopy. Acta Mater 129:482-491. https://doi. org/10.1016/j.actamat.2017.03.015

16. Wing BL, Halloran JW (2017) Microstress in the matrix of a melt-infiltrated SiC/SiC CMC. J Am Ceram Soc 100(11):52865294. https://doi.org/10.1111/jace. 15038

17. Radhika N, Raghu N (2015) Parametric study of dry sliding wear behavior of functionally graded $\mathrm{Al}$ LM25/Si3N4 composite by response surface methodology. Adv Compos Lett 24(6):130-136. https://doi.org/10.1177/096369351502400602

18. Curtin WA, Ahn BK, Takeda N (1998) Modelling brittle and tough stress-strain behaviour in unidirectional CMCs. Acta Mater 46(10):3409-3420. https://doi.org/10.1016/S1359-6454(98) 00041-X

19. Woodford D, Donald AAS, John MS, Timms L, Palko JE (1993) Testing the tensile properties of ceramic-matrix composites. J Min Met Mater Soc 45(5):57-63. https://doi.org/10.1007/BF032 23222

20. Naslain RR (1998) The design of the fiber-matrix interfacial zone in CMCs. Compos Part A Appl Sci Manuf 29(9-10):1145-1155. https://doi.org/10.1016/S1359-835X(97)00128-0

21. Lu MY, Han BH, He WH, Cheng ZG, Yu JF (2021) The strength of the CMCs under the influence of pore is reviewed. J Phys Conf Ser 1777(1):012027. https://doi.org/10.1088/1742-6596/1777/1/ 012027

22. Binner J, Porter M, Baker B, Zou J, Vinothini V, Diaz VR, Angio AD, Ramanujam P, Zhang T, Murthy TSRC (2020) Selection, processing, properties and applications of ultra-high temperature ceramic matrix composites, UHTCMCs - a review. Int Mater Rev 65(7):389-444. https://doi.org/10.1080/09506608.2019.1652006

23. Verrilli MJ, Opila E, Calomino A, Kiser JD (2002) Effect of environment on stress-rupture behaviour of a carbon fiber-reinforced silicon carbide (C/SiC) CMC. J Am Ceram Soc 87(8):15361542. https://doi.org/10.1111/j.1551-2916.2004.01536.x

24. Gong Y, Qu S, Yang Y, Liang C, Li P, She Y (2019) Some observations in grinding $\mathrm{SiC}$ and silicon carbide CMC material. Int $\mathrm{J}$ Adv Manuf Technol 103(5):3175-3186. https://doi.org/10.1007/ s00170-019-03735-w

25. Brennan JJ, Prewo KM (1982) Silicon carbide fiber reinforced glass-CMCs exhibiting high strength and toughness. J Mater Sci 17(8):2371-2383. https://doi.org/10.1007/BF00543747

26. Kaya H (1999) The application of ceramic-matrix composites to the automotive ceramic gas turbine. Compos Sci Technol 59(6):861-872. https://doi.org/10.1016/S0266-3538(99)00016-0
27. Xu Y, Zhang W (2009) Numerical prediction of the effective coefficient of thermal expansion of 3D braided $\mathrm{C} / \mathrm{SiC}$ composite. Int J Simul Multidiscip Des Opt 3(4):443-448. https://doi.org/ 10.1051/ijsmdo/2009021

28. Qu S, Gong Y, Yang Y, Cai M, Sun Y (2018) Surface topography and roughness of silicon carbide CMCs. Ceram Int 44(12):14742-14753. https://doi.org/10.1016/j.ceramint.2018. 05.104

29. Harshavardhan K, Nagendran S, Shanmugasundaram A, Sankar SP, Kowshik KS (2021) Investigating the effect of reinforcing $\mathrm{SiC}$ and graphite on aluminium alloy brake rotor using plasma spray process. Mater Today Proc 38(5):2706-2712. https://doi. org/10.1016/j.matpr.2020.08.484

30. Liu Y, Cheng L, Zhang L, Hua Y, Yang W (2008) Microstructure and properties of particle reinforced silicon carbide and silicon nitride ceramic matrix composites prepared by chemical vapor infiltration. Mater Sci Eng A 475(1-2):217-223. https://doi.org/ 10.1016/j.msea.2007.04.031

31. Fang Y, Yu F, White KW (2004) Bimodal microstructure in silicon nitride-barium aluminium silicate ceramic-matrix composites by pressureless sintering. J Am Ceram Soc 83(7):1828-1830. https://doi.org/10.1111/j.1151-2916.2000.tb01475.x

32. Vivekananthan M, Ahilan C, Sakthivelu S, Saravanakumar M (2020) A primary study of density and compressive strength of the silicon nitride and titanium nitride ceramic composite. Mater Today Proc 33(7):2741-2745. https://doi.org/10.1016/j.matpr. 2020.01 .570

33. Yu F, Nagarajan N, Fang Y, White KW (2001) Microstructural control of a $70 \%$ Si3N4-30\% barium aluminium silicate selfreinforced composite. J Am Ceram Soc 84(1):13-22. https://doi. org/10.1111/j.1151-2916.2001.tb00601.x

34. Becher PF (1991) Microstructural design of toughened ceramics. J Am Ceram Soc 74(2):255-269. https://doi.org/10.1111/j. 1151-2916.1991.tb06872.x

35. Becher PF, Hwang SL, Hsueh CH (1995) Using microstructure to attack the brittle nature of silicon nitride ceramics. Mater Res Soc Bull 20(2):23-27. https://doi.org/10.1557/S08837694000491 74

36. Guo S, Hirosaki N, Yamamoto Y, Nishimura T, Mitomo M (2001) Improvement of high-temperature strength of hotpressed sintering silicon nitride with $\mathrm{Lu} 2 \mathrm{O} 3$ addition. Scr Mater 45(7):867-874. https://doi.org/10.1016/S1359-6462(01)01111-3

37. Klemm H (2010) Silicon nitride for high-temperature applications. J Am Ceram Soc 93(6):1501-1522. https://doi.org/10. 1111/j.1551-2916.2010.03839.x

38. Hoffmann MJ (1995) Relationship between microstructure and mechanical properties of silicon nitride ceramics. Pure Appl Chem 67(6):939-946. https://doi.org/10.1351/pac199567060939

39. Hoffmann MJ, Pitsaw G (1994) Tailored microstructures of silicon nitride ceramics. Pure Appl Chem 66(9):1807-1814. https:// doi.org/10.1351/pac199466091807

40. Raj N, Radhika N (2019) Tribological characteristics of LM13/ $\mathrm{Si} 3 \mathrm{~N} 4 / \mathrm{Gr}$ hybrid composite at elevated temperature. SILICON 11(2):947-960. https://doi.org/10.1007/s12633-018-9893-1

41. Jayan V, Radhika N (2020) Taguchi's technique in optimization of process parameters on wear behaviour of $\mathrm{Cu} / \mathrm{Si} 3 \mathrm{~N} 4$ metal matrix composite. Mater Today Proc 24(2):1052-1063. https:// doi.org/10.1016/j.matpr.2020.04.419

42. Radhika N, Jefferson JA (2019) Studies on mechanical and abrasive wear properties of $\mathrm{Cu}-\mathrm{Ni}-\mathrm{Si} / \mathrm{Si} 3 \mathrm{~N} 4$ functionally graded composite. SILICON 11(2):627-641. https://doi.org/10.1007/ s12633-018-9957-2

43. Radhika N (2018) Comparison of the mechanical and wear behaviour of aluminium alloy with homogeneous and 
functionally graded silicon nitride composites. Sci Eng Compos Mater 25(2):261-271. https://doi.org/10.1515/secm-2015-0160

44. Sajgalik P, Dusza J, Hoffmann MJ (1995) Relationship between microstructure, toughening mechanisms, and fracture toughness of reinforced silicon nitride ceramics. J Am Ceram Soc 78(10):2619-2624. https://doi.org/10.1111/j.1151-2916.1995. tb08031.x

45. Goto Y, Tsuge A (1993) Mechanical properties of unidirectionally oriented $\mathrm{SiC}$-whisker- reinforced $\mathrm{Si} 3 \mathrm{~N} 4$ fabricated by extrusion and hot pressing. J Am Ceram Soc 76(6):1420-1424. https:// doi.org/10.1111/j.1151-2916.1993.tb03920.x

46. Ge P, Cheng Y, Sun K (2019) Structure and performance of Si3N4/SiC/CNT composite fibres. Ceram Int 45(10):1267721268. https://doi.org/10.1016/j.ceramint.2019.03.099

47. Pezzotti G (1993) Effect of HIP sintering on the crystal structure and fracture behaviour of $\mathrm{SiC}$ platelets embedded in Si3N4 matrix. J Ceram Soc Japan 101(1178):1131-1136. https://doi. org/10.2109/jcersj.101.1131

48. Wang CA, Huang Y, Zan Q, Zou L, Cai S (2002) Control of composition and structure in laminated silicon nitride/boron nitride composites. J Am Ceram Soc 85(10):2457-2461. https://doi.org/ 10.1111/j.1151-2916.2002.tb00480.x

49. Barta J, Manela M, Fischer R (1985) Si3N4 and Si2N2O for high performance radomes. Mater Sci Eng 71:265-272. https://doi. org/10.1016/0025-5416(85)90236-8

50. Liu Y, Cheng L, Zhang L, Hua Y, Yang W (2008) Microstructure and properties of particle reinforced silicon carbide and silicon nitride CMCs prepared by chemical vapor infiltration. Mater Sci Eng A 475(1-2):217-223. https://doi.org/10.1016/j.msea.2007. 04.031

51. Qi G, Zhang C, Hu H, Cao F, Wang S, Jiang Y, Li B (2005) Crystallization behaviour of three-dimensional silica fiber reinforced silicon nitride composite. J Cryst Growth 284(12):293-296. https://doi.org/10.1016/j.jcrysgro.2005.06.039

52. Yu F, Ortiz Longo CR, White KW, Hunn DL (1999) The microstructural characterization of in situ grown Si3N4 whisker reinforced barium aluminium silicate CMC. J Mater Sci 34(12):2821-2835. https://doi.org/10.1023/A:1004623015929

53. Sinha RK, Sridhar K, Purohit R, Malviya RK (2020) Effect of nano $\mathrm{SiO} 2$ on properties of natural fiber reinforced epoxy hybrid composite: A review. Mater Today Proc 26(2):31833186. https://doi.org/10.1016/j.matpr.2020.02.657

54. Ohnabea H, Masakia S, Onozukaa M, Miyaharab K, Sasa T (1999) Potential application of ceramic matrix composites to aero-engine components. Compos A Appl Sci Manuf 30:489496. https://doi.org/10.1016/S1359-835X(98)00139-0

55. Alomayri T, Raza A, Shaikh F (2021) Effect of nano SiO2 on mechanical properties of micro-steel fibers reinforced geopolymer composites. Ceram Int 47(23):33444-33453. https://doi. org/10.1016/j.ceramint.2021.08.251

56. Liu D, Niu HW, Zhou YH, Song XG, Tang DY, Feng JC (2015) Brazing continuous carbon fiber reinforced Li2O-Al2O3-SiO2 ceramic matrix composites to Ti-6Al-4V alloy using $\mathrm{Ag}-\mathrm{Cu}-$ Ti active filler metal. Mater Des 87:42-48. https://doi.org/10. 1016/j.matdes.2015.08.005

57. Swami MC, Dabade BM (2021) Effect Of Sea Water On Mechanical Properties Of Glass Fiber Reinforced Polymer With Silicon Dioxide \& Silicon Oil Fillers. Mater Today Proc. https://doi.org/10.1016/j.matpr.2021.06.095

58. Lee WY, Lara-Curzio E, Karren L (2005) Multilayered Oxide Interphase Concept for Ceramic-Matrix Composites. J Am Ceram Soc 81(3):717-720. https://doi.org/10.1111/j.11512916.1998.tb02396.x

59. Zhao J, Liebscher M, Michel A, Schneider K, Foest R, Frohlich M, Quade A, Mechtcherine V (2020) Plasma-generated silicon oxide coatings of carbon fibres for improved bonding to mineral-based impregnation materials and concrete matrices. Cem Concr Compos 114:103667. https://doi.org/10.1016/j. cemconcomp.2020.103667

60. Li A, Jia Y, Li Z, Ren S, Zhang F, He Q (2021) Study on the friction and wear properties of zinc oxide/silicon dioxide composite-coated paper mulch film. J King Saud Univ Eng Sci. https://doi.org/10.1016/j.jksues.2021.12.004

61. Qadir A, Pinke P, Dusza J (2020) Silicon nitride based composites with the addition of CNTs: A review of recent progress challenges and future prospects. Mater 13(12):2799. https:// doi.org/10.3390/ma13122799

62. Tian CY, Jiang H (2018) Preparation and mechanical properties of carbon nanotube silicon nitride nano ceramic matrix composite. IOP Conf Ser Mater Sci Eng 292(1):012076. https:// doi.org/10.1088/1757-899X/292/1/012076

63. Gábrišová Z, Švec P, Brusilová A (2020) Microstructure and selected properties of Si3N4 + SiC composite. Manuf Technol 20(3):293-299. https://doi.org/10.21062/mft.2020.056

64. Guan J, Cheng L, Li M (2018) Microstructure and mechanical properties of Si3N4-Fe3Si composites prepared by gaspressure sintering. Mater 11(7):1206. https://doi.org/10.3390/ ma11071206

65. Frazer D, Abad MD, Krumwiede D, Back CA, Khalifa HE, Deck CP, Hosemann P (2015) Localized mechanical property assessment of $\mathrm{SiC} / \mathrm{SiC}$ composite materials. Compos Part A Appl Sci 70:93-101. https://doi.org/10.1016/j.compositesa. 2014.11.008

66. Zinkle SJ, Snead LL (1998) Thermophysical and mechanical properties of $\mathrm{SiC} / \mathrm{SiC}$ composites. Int Nuc Info Sys 30(35):93100. https://doi.org/10.2172/330618

67. Wu S, Cheng L, Dong N, Zhang L, Xu Y (2006) Flexural strength distribution of 3D SiC/SiC composite. J Mater Eng Perform 15(6):712-716. https://doi.org/10.1361/105994906X150768

68. Chen M, Qiu H, Zhang B, Ma X, Luo W, Liu S, Liu S (2019) Effect of processing technology on structural stability of SiC/ $\mathrm{SiBCZr}$ ceramic matrix composites. Ceram Int. https://doi.org/ 10.1016/j.ceramint.2021.12.262

69. Zhang R, Li W, Liu Y, Wang C, Wang J, Yang X, Cheng L (2015) Machining parameter optimization of $\mathrm{C} / \mathrm{SiC}$ composites using high power picosecond laser. Appl Surf Sci 330:321-331. https:// doi.org/10.1016/j.apsusc.2015.01.010

70. Xu Y, Cheng L, Zhang L, Yin H, Yin X (2001) Mechanical properties of 3D fiber reinforced $\mathrm{C} / \mathrm{SiC}$ composites. Mater Sci Eng A 300(1-2):196-202. https://doi.org/10.1016/s0921-5093(00) 01533-1

71. Kopeliovich D (2014) Advances in the manufacture of CMCs using infiltration techniques. Adv Cerm Mat Comp 79-108. https://doi.org/10.1533/9780857098825.1.79

72. Lee SH, Weinmann M, Aldinger F (2008) Processing and properties of C/Si-B-C-N fiber reinforced ceramic matrix composites prepared by precursor impregnation and pyrolysis. Acta Mater 56(7):1529-1538. https://doi.org/10.1016/j.actamat.2007.12.001

73. Pirzada TJ, Singh S, De Meyere R, Earp P, Galano M, James Marrow T (2021) Effects of polymer infiltration processing (PIP) temperature on the mechanical and thermal properties of Nextel 312 fibre SiCO ceramic matrix composites. Compos Part A Appl Sci Manuf 140:106197. https://doi.org/10.1016/j.compositesa. 2020.106197

74. Yuan Q, Chai ZF, Huang ZR, Huang Q. A new precursor of liquid and curable polysiloxane for highly cost-efficient SiOCbased composites. Ceram Int 45(6):7044-7048. https://doi.org/ 10.1016/j.ceramint.2018.12.206

75. Yu Y, Liu Y, Zhang Z, Zhang J (2020) Fabrication of high fracture-strength and gas-tightness PDC films via PIP process for pressure sensor application. J Am Ceram Soc 103(6):3541-3551. https://doi.org/10.1111/jace.17063 
76. Liu L, Li X, Xing X, Zhou C, Hu H (2008) A modified polymethylsilane as the precursor for CMCs. J Organomet Chem 693(6):917-922. https://doi.org/10.1016/j.jorganchem.2007.10. 007

77. Wang HZ, Li XD, Ma J, Li GY, Hu TJ (2012) Fabrication of multi-walled carbon nanotube-reinforced carbon fiber/silicon carbide composites by polymer infiltration and pyrolysis process. Compos Sci Technol 72(3):461-466. https://doi.org/10.1016/j. compscitech.2011.12.009

78. Nakamura T, Oka T, Imanari K, Shinohara KI, Ishizaki M (2014) Development of CMC turbine parts for aero engines. Eng Rev 47(1):29-32

79. Yan C, Liu R, Cao Y, Zhang C, Zhang D (2014) Preparation and properties of 3D needle-punched $\mathrm{C} / \mathrm{ZrC}-\mathrm{SiC}$ composites by polymer infiltration and pyrolysis process. Ceram Int 40(7):1096110970. https://doi.org/10.1016/j.ceramint.2014.03.099

80. Aparicio IE, Fishpool DT, Diaz VR, Dorey RA, Yeomans JA (2021) Evaluation of polymer matrix composite manufacturing routes for production of an oxide/oxide ceramic matrix composite. J Eur Ceram Soc. https://doi.org/10.1016/j.jeurceramsoc. 2021.12.059

81. Langlais $F$ (2000) Chemical vapor infiltration processing of CMCs. Comp Compos Mater 5:611-644. https://doi.org/10. 1016/B0-08-042993-9/00105-4

82. Al-Dheylan KA (2004) The low velocity impact loading of A12O3/SiC whisker reinforced ceramic composite. J Mater Process Technol 155:1986-1994. https://doi.org/10.1016/j.jmatp rotec. 2004.04 .398

83. Kragness ED, Amateau MF, Messing GL (1991) Processing and characterization of laminated $\mathrm{SiC}$ whisker reinforced $\mathrm{Al} 2 \mathrm{O} 3$. J Compos Mater 25(4):416-432. https://doi.org/10.1177/00219 9839102500404

84. Shin D (2005) Fabrication and mechanical properties of silicon nitride laminate composites. J Ceram Process Res 6(3):263-265

85. Xie Y, Cheng L, Li L, Mei H, Zhang L (2013) Fabrication of laminated $\mathrm{SiCw} / \mathrm{SiC}$ ceramic composites by CVI. J Eur Ceram Soc 33(10):1701-1706. https://doi.org/10.1016/j.jeurceramsoc. 2013.02.019

86. Deck CP, Khalifa HE, Sammuli B, Hilsabeck T, Back CA (2012) Fabrication of $\mathrm{SiC}-\mathrm{SiC}$ composites for fuel cladding in advanced reactor designs. Prog Nucl 57:38-45. https://doi.org/10.1016/j. pnucene.2011.10.002

87. Tang ZH, Qu DN, Xiong J, Zou ZQ (2003) Effects of infiltration conditions on the densification behavior of carbon/carbon composites prepared by a directional-flow thermal gradient CVI process. Carbon 41(14):2703-2710. https://doi.org/10.1016/ S0008-6223(03)00374-9

88. Christin F (2002) Design, fabrication and application of thermostructural composites (TSC) like $\mathrm{C} / \mathrm{C}, \mathrm{C} / \mathrm{SiC}$ and $\mathrm{SiC} / \mathrm{SiC}$ composites. Adv Eng Mater 4(12):903-912. https://doi.org/10. 1002/adem.200290001

89. Krenkel W (2004) Carbon fiber reinforced CMC for high-performance structures. Int J Appl Ceram Technol 1(2):188-200. https://doi.org/10.1111/j.1744-7402.2004.tb00169.x

90. Krenkel W, Berndt F (2005) C/C-SiC composites for space applications and advanced friction systems. Mater Sci Eng A 412(1-2):177-181. https://doi.org/10.1016/j.msea.2005.08.204

91. Lamouroux F, Bertrand S, Pailler R, Naslain R, Cataldi M (1999) Oxidation-resistant carbon-fiber-reinforced ceramic-matrix composites. Compos Sci Technol 5(7):1073-1085. https://doi.org/10. 1016/S0266-3538(98)00146-8

92. Chen L, Yin X, Fan X, Chen M, Ma X, Cheng L, Zhang L (2015) Mechanical and electromagnetic shielding properties of carbon fiber reinforced silicon carbide matrix composites. Carbon 95:10-19. https://doi.org/10.1016/j.carbon.2015.08.011
93. Fan S, Zhang L, Xu Y, Cheng L, Lou J, Zhang J, Yu L (2007) Microstructure and properties of 3D needle-punched carbon/ silicon carbide brake materials. Compos Sci Technol 67(1112):2390-2398. https://doi.org/10.1016/j.compscitech.2007.01. 008

94. Wang J, Cao L, Liu Y, Zhang Y, Fang H, Chen J (2020) Fabrication of improved flexural strength $\mathrm{C} / \mathrm{SiC}$ composites via LA-CVI method using optimised spacing of mass transferred channels. J Eur Ceram Soc 40(8):2828-2833. https://doi.org/10.1016/j.jeurc eramsoc.2020.02.050

95. Naslain RR, Pailler R, Bourrat X, Bertrand S, Heurtevent F, Dupel P, Lamouroux F (2001) Synthesis of highly tailored CMCs by pressure pulsed CVI. Solid State Ion 141:541-548. https://doi. org/10.1016/S0167-2738(01)00743-3

96. Hillig WB (1988) Melt infiltration approach to CMCs. J Am Ceram Soc 71(2):96-99. https://doi.org/10.1111/j.1151-2916. 1988.tb05840.x

97. Morscher GN, Pujar VV (2004) Melt infiltrated SiC composites for gas turbine engine applications. Am Soc Mech Eng Turbo Expo 41677:353-359. https://doi.org/10.1115/GT2004-53196

98. Bhatti AR, Farries PM (2000) Preparation of long-fiber-reinforced dense glass and ceramic matrix composites. Comp Compos Mater 4:645-667. https://doi.org/10.1016/B0-08-042993-9/ 00107-8

99. Sun X, Yin X, Fan X, Ma X, Cao X, Cheng L, Zhang L (2018) Oxidation resistance of $\mathrm{SiC} / \mathrm{SiC}$ composites containing $\mathrm{SiBC}$ matrix fabricated by liquid silicon infiltration. J Eur Ceram Soc 38(2):479-485. https://doi.org/10.1016/j.jeurceramsoc.2017.09. 004

100. Morscher GN, Yun HM, Dicarlo JA, Thomas-Ogbuji L (2002) Effect of a boron nitride interphase that debonds between the interphase and the matrix in $\mathrm{SiC} / \mathrm{SiC}$ composites. J Am Ceram Soc 87(1):104-112. https://doi.org/10.1111/j.1551-2916.2004. 00104.x

101. Sun M, Bai Y, Li M, Fan S, Cheng L (2018) In-situ fabrication of laminated $\mathrm{SiC} / \mathrm{TiSi} 2$ and $\mathrm{SiC} / \mathrm{Ti} 3 \mathrm{SiC} 2$ ceramics by liquid silicon infiltration. Ceram Int 44(10):11410-11416. https://doi.org/10. 1016/j.ceramint.2018.03.194

102. Zhou Y, Sun Z (1999) Microstructure, and mechanism of damage tolerance for Ti3SiC2 bulk ceramics. Mater Res Innov 2(6):360 363. https://doi.org/10.1007/s100190050114

103. Zhen T, Barsoum MW, Kalidindi SR (2005) Effects of temperature, strain rate and grain size on the compressive properties of Ti3SiC2. Acta Mater 53(15):4163-4171. https://doi.org/10. 1016/j.actamat.2005.05.020

104. Gu GX, Takaffoli M, Buehler MJ (2017) Hierarchically enhanced impact resistance of bioinspired composites. Adv Mater 29(28):1700060. https://doi.org/10.1002/adma.201700060

105. Ballarini R, Heuer AH (2007) Secrets in the shell: The body armour of the queen conch is much tougher than comparable synthetic materials. Am Sci 95(5):422-429. https://www.jstor. org/stable/i27859013

106. Wagner RS, Sinha AK, Sheng TT, Levinstein HJ, Alexander FB (1974) Tungsten metallization for LSI applications. J Vac Sci Technol 11(3):582-590. https://doi.org/10.1116/1.1318073

107. Kovalčíková A, Kurek P, Balko J, Dusza J, Šajgalík P, Mihaliková $M$ (2014) Effect of the counterpart material on wear characteristics of silicon carbide ceramics. Int J Refract Hard Met 44:12-18. https://doi.org/10.1016/j.ijrmhm.2014.01.006

108. Krenkel W (2003) C/C-SiC composites for hot structures and advanced friction systems. Ceram Eng Sci Proc 24(4):583-594. https://doi.org/10.1002/9780470294826.ch85

109. Zhao Y-W, Wang Y-J, Hua-Xin Peng Yu, Zhou, (2012) Dense sub-micron-sized $\mathrm{ZrC}-\mathrm{W}$ composite produced by reactive melt infiltration at $1200{ }^{\circ} \mathrm{C}$. Int J Refract Hard Met 30:196-199. https://doi.org/10.1016/j.ijrmhm.2011.08.009 
110. Han Bo, Zhang W, Gao De, Zhou C, Xia K, Gao Q, Jinping Wu (2020) Encapsulating tin oxide nanoparticles into holey carbon nanotubes by melt infiltration for superior lithium and sodium ion storage. J Power Sources 449:227564. https://doi.org/10.1016/j. jpowsour.2019.227564

111. Wagner F, Garcia DE, Krupp A, Claussen N (1999) Interpenetrating Al2O3-TiAl3 alloys produced by reactive infiltration. $\mathrm{J}$ Eur Ceram Soc 19(13-14):2449-2453. https://doi.org/10.1016/ S0955-2219(99)00133-8

112. Magne P, Paranhos MPG, Burnett LH (2010) New zirconia primer improves bond strength of resin-based cements. Dent Mater 26(4):345-352. https://doi.org/10.1016/j.dental.2009.12. 005

113. Kern M (2015) Bonding to oxide ceramics - Laboratory testing versus clinical outcome. Dent Mater 31(1):8-14. https://doi.org/ 10.1016/j.dental.2014.06.007

114. Casucci A, Monticelli F, Goracci C, Mazzitelli C, Cantoro A, Papacchini F, Ferrari M (2011) Effect of surface pre-treatments on the zirconia ceramic resin cement micro tensile bond strength. Dent Mater 27(10):1024-1030. https://doi.org/10.1016/j.dental. 2011.07.002

115. Campos TMB, Ramos NC, Machado JPB, Bottino MA, Souza ROA, Melo RM (2016) A new silica-infiltrated Y-TZP obtained by the sol-gel method. J Dent 48:55-61. https://doi.org/10.1016/j. jdent.2016.03.004

116. Zhang Y, Chai H, Lee JW, Lawn BR (2012) Chipping resistance of graded zirconia ceramics for dental crowns. J Dent Res 91(3):311-315. https://doi.org/10.1177/0022034511434356

117. Souza RO, Valandro LF, Melo RM, Machado JP, Bottino MA, Ozcan M (2013) Air-particle abrasion on zirconia ceramic using different protocols: Effects on biaxial flexural strength after cyclic loading, phase transformation and surface topography. J Mech Behav Biomed Mater 26:155-163. https://doi.org/10. 1016/j.jdent.2017.05.021

118. Zhang Y, Lawn BR, Rekow ED, Thompson VP (2004) Effect of sandblasting on the long-term performance of dental ceramics. J Biomed Mater Res Part B Appl Biomater J 71(2):381-386. https://doi.org/10.1002/jbm.b.30097

119. Matsui K, Ohgai M (2002) Formation mechanism of hydrous zirconia particles produced by hydrolysis of $\mathrm{ZrOCl} 2$ solutions: IV, effects of $\mathrm{ZrOCl} 2$ concentration and reaction temperature. J Am Ceram Soc 85:545-553. https://doi.org/10.1111/j.11512916.2002.tb00131.x

120. Zhang Q, Shen J, Wang J, Wu G, Chen L (2000) Sol-gel derived $\mathrm{ZrO} 2-\mathrm{SiO} 2$ highly reflective coatings. Int J Inorg Mater 2(4):319-323. https://doi.org/10.1016/S1466-6049(00)00037-4

121. Xi XM, Yang XF (1996) Sintering behaviour of (Y2O3-ZrO2 gels). J Mater Sci 31(10):2697-2703. https://doi.org/10.1007/ BF00687303

122. Rambo CR, Cao J, Sieber H (2004) Preparation and properties of highly porous, biomorphic YSZ ceramics. Mater Chem Phys 87(2-3):345-352. https://doi.org/10.1016/j.matchemphys.2004. 05.031

123. Singh M, Yee BM (2004) Reactive processing of environmentally conscious, biomorphic ceramics from natural wood precursors. J Eur Ceram Soc 24(2):209-217. https://doi.org/10.1016/S09552219(03)00244-9

124. Rambo CR, Cao J, Rusina O, Sieber H (2005) Manufacturing of biomorphic ( $\mathrm{Si}, \mathrm{Ti}, \mathrm{Zr}$ )-carbide ceramics by sol-gel processing. Carbon 43(6):1174-1183. https://doi.org/10.1016/j.carbon.2004. 12.009

125. Cao J, Rambo CR, Sieber H (2004) Preparation of porous Al2O3ceramics by biotemplating of wood. J Porous Mater 11(3):163172. https://doi.org/10.1023/B:JOPO.0000038012.58705.c9
126. Li X, Yin X, Zhang L, Cheng L, Qi Y (2009) Mechanical and dielectric properties of porous $\mathrm{Si} 3 \mathrm{~N} 4-\mathrm{SiO} 2$ composite ceramics. Mater Sci Eng A 500(1-2):63-69. https://doi.org/10.1016/j. msea.2008.09.066

127. Zou C, Zhang C, Li B, Cao F, Wang S (2012) Improved properties and microstructure of porous silicon nitride/silicon oxide composites prepared by sol-gel route. Mater Sci Eng A 556:648652. https://doi.org/10.1016/j.msea.2012.07.042

128. Nazeri A, Bescher E, Mackenzie JD (2009) Ceramic composites by the sol-gel method: a review. Ceram Eng Sci Proc 14(1112):1-19. https://doi.org/10.1002/9780470314272.ch1

129. Cheng L, Xu Y, Zhang L, Gao R (2001) Effect of glass sealing on the oxidation behavior of three dimensional $\mathrm{C} / \mathrm{SiC}$ composites in air. Carbon 39(8):1127-1133. https://doi.org/10.1016/S00086223(00)00148-2

130. Ogasawara T, Ishikawa T, Ito H, Watanabe N, Davies IJ (2001) Multiple cracking, and tensile behaviour for an orthogonal 3-D woven Si-Ti-C-O fiber/Si-Ti-C- O matrix composite. J Am Ceram Soc 84(7):1565-1574. https://doi.org/10.1111/j.1151-2916.2001. tb00878.x

131. Suzuki M, Tanaka Y, Inoue Y, Miyamoto N, Sato M, Goda K (2003) Uniformization of boron nitride coating thickness by continuous chemical vapor deposition process for interphase of $\mathrm{SiC} /$ SiC composites. J Ceram Soc Japan 111(1300):865-871. https:// doi.org/10.2109/jcersj.111.865

132. He XB, Yang H (2005) Preparation of SiC fiber-reinforced SiC composites. J Mater Process Technol 159(1):135-138. https:// doi.org/10.1016/j.jmatprotec.2003.10.028

133. Dong S, Katoh Y, Kohyama A (2003) Preparation of SiC/SiC composites by hot pressing using tyranno-SA fiber as reinforcement. J Am Ceram Soc 86(1):26-32. https://doi.org/10.1111/j. 1151-2916.2003.tb03272.x

134. Dong S, Katoh Y, Kohyama A (2003) Processing optimization and mechanical evaluation of hot pressed 2D tyranno-SA/SiC composites. J Eur Ceram Soc 23(8):1223-1231. https://doi.org/ 10.1016/S0955-2219(02)00298-4

135. Taguchi T, Igawa N, Yamada R, Jitsukawa S (2005) Effect of thick $\mathrm{SiC}$ interphase layers on microstructure, mechanical and thermal properties of reaction-bonded $\mathrm{SiC} / \mathrm{SiC}$ composites. J Phys Chem Solids 66(2-4):576-580. https://doi.org/10.1016/j. jpcs.2004.06.034

136. Xu Y, Cheng L, Zhang L, Yin H, Yin X (2001) High toughness, $3 \mathrm{D}$ textile, $\mathrm{SiC} / \mathrm{SiC}$ composites by chemical vapor infiltration. Mater Sci Eng A 318(1-2):183-188. https://doi.org/10.1016/ S0921-5093(01)01303-X

137. Kotani M, Inoue T, Kohyama A, Katoh Y, Okamura K (2003) Effect of SiC particle dispersion on microstructure and mechanical properties of polymer-derived $\mathrm{SiC} / \mathrm{SiC}$ composite. Mater Sci Eng A 357(1-2):376-385. https://doi.org/10.1016/S09215093(03)00206-5

138. Zhu Y, Huang Z, Dong S, Yuan M, Jiang D (2008) Manufacturing 2D carbon-fiber-reinforced $\mathrm{SiC}$ matrix composites by slurry infiltration and PIP process. Ceram Int 34(5):1201-1205. https:// doi.org/10.1016/j.ceramint.2007.02.014

139. Fan X, Yin X, Wang L, Cheng L, Zhang L (2013) Processing, microstructure and ablation behavior of $\mathrm{C} / \mathrm{SiC}-\mathrm{Ti}_{3} \mathrm{SiC}_{2}$ composites fabricated by liquid silicon infiltration. Corros Sci 74:98105. https://doi.org/10.1016/j.corsci.2013.04.029

140. Dean JA (1990) Lange's handbook of chemistry. Mater Manuf Process, New York: McGraw-Hill 5(4):687-688. https://doi.org/ 10.1080/10426919008953291

141. Singh S, Yin J, Feng L, Mondal DP, Kim D, Lee SH (2020) Significance of modification of slurry infiltration process for the precursor impregnation and pyrolysis process of $\mathrm{SiCf} / \mathrm{SiC}$ 
composites. J Eur Ceram Soc 40(5):2245-2251. https://doi.org/ 10.1016/j.jeurceramsoc.2020.01.009

142. Hernandez MA, Bakoglidis KD, Xiao P (2019) A new slurry infiltration method to enhance the wear resistance of bulk graphite with development of reinforced graphitic composites including $\mathrm{SiC}$ or $\mathrm{Si}_{3} \mathrm{~N}_{4}$ hard particles. J Eur Ceram Soc 39(6):19841992. https://doi.org/10.1016/j.jeurceramsoc.2019.01.053

143. Stalin M, Rajaguru K, Rangaraj L (2020) Processing of Cf/ $\mathrm{SiC}$ composites by hot pressing using polymer binders followed by polymer impregnation and pyrolysis. J Eur Ceram Soc 40(2):290-297. https://doi.org/10.1016/j.jeurceramsoc.2019.09. 047

144. Wang H-Z, Li X-D, Ma J, Li G-y, Tian-jiao Hu (2012) Fabrication of multi-walled carbon nanotube-reinforced carbon fiber/ silicon carbide composites by polymer infiltration and pyrolysis process. Compos Sci Technol 72:461-466. https://doi.org/10. 1016/j.compscitech.2011.12.009

145. Xiongn C, Li T, Zhao T, Khan M, Wang J, Ji X, Li H, Liu W, Shang Y (2016) Preparation of C/C-SiC composite by low temperature compression molding-liquid silicon infiltration and its application in automobile brake. Ceram Int 42(1):1057-1062. https://doi.org/10.1016/j.ceramint.2015.09.030

146. Liedtke V, Huertas Olivares I, Langer M, Haruvy YF (2007) Sol-gel-based carbon/silicon carbide. J Eur Ceram Soc 27:12671272. https://doi.org/10.1016/j.jeurceramsoc.2006.05.045

147. Veličković S, Stojanović B, Ivanović L, Miladinović S, Milojević $S$ (2019) Application of nanocomposites in the automotive industry. Mob Veh Mech 45(3):51-64. https://doi.org/10.24874/mvm. 2019.45.03.05

148. Sam M, Radhika N (2021) Comparative study on reciprocal tribology performance of mono-hybrid ceramic reinforced Al-9Si3Cu graded composites. SILICON 13(8):2671-2687. https://doi. org/10.1007/s12633-020-00623-x

149. Durowaye SI, Sekunowo OI, Lawal AI, Ojo OE (2017) Development and characterisation of iron millscale particle reinforced ceramic matrix composite. J Taibah Univ Sci 11(4):634-644. https://doi.org/10.1016/j.jtusci.2016.08.005

150. Basutkar AG, Kolekar A (2015) A review on properties and applications of ceramic matrix composite. Int J Res Sci Innov 2:28. https://doi.org/10.13140/RG.2.2.20304.53766

151. Ran L-P, Rao F, Peng Ke, Yin H, Yi M-Z (2019) Preparation and properties of $\mathrm{C} / \mathrm{C}-\mathrm{ZrB} 2-\mathrm{SiC}$ composites by high-solidloading slurry impregnation and polymer infiltration and pyrolysis (PIP). Trans Nonferrous Met Soc 29:2141-2150. https:// doi.org/10.1016/S1003-6326(19)65120-4

152. Shim G, Kim S-H, Kim S, Han I-S, Bang H-J, Seong Y-H, Lee S, Kim WS, Shin K (2022) Influence of pyrolysis and melt infiltration temperatures on the mechanical properties of SiCf/ SiC composites. Ceram Int 48:1532-1541. https://doi.org/10. 1016/j.ceramint.2021.09.231

153. Rahman A, Zunjarrao SC, Singh RP (2016) Effect of degree of crystallinity on elastic properties of silicon carbide fabricated using polymer pyrolysis. J Eur Ceram Soc 36(14):3285-3292. https://doi.org/10.1016/j.jeurceramsoc.2016.06.010

154. Zeng X, Yang Y, Deng Q, Wang Bo, Zhang C (2021) Thermal shock response behaviour of carbon fibre reinforced silicon carbide matrix composites prepared by chemical vapour infiltration at different heating rates. Ceram Int 47(22):3145731469. https://doi.org/10.1016/j.ceramint.2021.08.022

155. Panakarajupally RP, Presby MJ, Manigandan K, Zhou J, Chase GG, Morscher GN (2019) Thermomechanical Characterization of $\mathrm{SiC} / \mathrm{SiC}$ Ceramic Matrix Composites in a Combustion Facility. Ceramics 2(2):407-425. https://doi.org/10.3390/ceram ics2020032

156. Sciti D, Silvestroni L, Monteverde F, Vinci A, Zoli L (2018) Introduction to $\mathrm{H} 2020$ project C3HARME - next generation ceramic composites for combustion harsh environment and space. Adv Appl Ceram 117:570-575. https://doi.org/10.1080/ 17436753.2018.1509822

157. An G, Liu H, Li H, Chen Z, Li J, Li Y (2019) SiBCN ceramic aerogel/graphene composites prepared via sol-gel infiltration process and polymer-derived ceramics (PDCs) route. Ceram Int 46(6):7001-7008. https://doi.org/10.1016/j.ceramint.2019.10. 267

158. Suryanarayanan K, Praveen R, Raghuraman S (2013) Silicon carbide reinforced aluminium metal matrix composites for aerospace applications: a literature review. Int J Innov Res Sci Eng Technol 2(11):6336-6344

159. Ramos NC, Alves LMM, Ricco P, Santos GMAS, Bottino MA, Campos TMB, Melo RM (2020) Strength and bondability of a dental Y-TZP after silica sol-gel infiltrations. Ceram Int 46:17018-17024. https://doi.org/10.1016/j.ceramint.2020.03. 288

160. Francis A (2018) Progress in polymer-derived functional siliconbased ceramic composites for biomedical and engineering applications. Mater Res Express 5(6):062003. https://doi.org/10.1088/ 2053-1591/aacd28

161. Aly K, Muhuri AK, Bradford PD (2021) Fabrication of scalable, aligned and low density carbon nanotube/silicon carbide hybrid foams by polysilazane infiltration and pyrolysis. J Eur Ceram Soc 41:3303-3313. https://doi.org/10.1016/j.jeurceramsoc.2020.12. 035

162. Han D, Mei H, Xiao S, Xia J, Jinlei Gu, Cheng L (2017) Porous $\mathrm{SiCnw} / \mathrm{SiC}$ ceramics with unidirectionally aligned channels produced by freeze-drying and chemical vapor infiltration. J Eur Ceram Soc 37(3):915-921. https://doi.org/10.1016/j.jeurcerams oc. 2016.10 .015

163. Xue T, Wang ZJW (2010) Preparation of porous SiC ceramics from waste cotton linter by reactive liquid $\mathrm{Si}$ infiltration technique. Mater Sci Eng A 527:7294-7298. https://doi.org/10. 1016/j.msea.2010.07.077

164. Baitalik S, Kayal N (2019) Thermal shock and chemical corrosion resistance of oxide bonded porous $\mathrm{SiC}$ ceramics prepared by infiltration technique. J Alloys Compd 781:289-301. https:// doi.org/10.1016/j.jallcom.2018.12.046

165. Liang X, Lia Y, Liu J, Sang S, Chen Y, Li B, Aneziris CG (2017) Improvement of the mechanical properties of $\mathrm{SiC}$ reticulated porous ceramics with optimized three-layered struts for porous media combustion. Ceram Int 43(4):3741-3747. https://doi.org/ 10.1016/j.ceramint.2016.12.007

166. Ghanem H, Alkhateeb E, Gerhard H, Popovska N (2009) Oxidation behavior of silicon carbide based biomorphic ceramics 7 prepared by chemical vapor infiltration and reaction technique. Ceram Int 35:2767-2774. https://doi.org/10.1016/j.ceramint. 2009.03.025

167. Ortona A, Fino P, D’Angelo C, Biamino S, D’Amico G, Gaia D, Gianella S (2012) Si-SiC-ZrB2 ceramics by silicon reactive infiltration. Ceram Int 38:3243-3250. https://doi.org/10.1016/j. ceramint.2011.12.030

168. Smeacetto F, Ferraris M, Salvo M, Ellacott SD, Ahmed A, Rawlings RD, Boccaccini AR (2008) Protective coatings for carbon bonded carbon fibre composites. Ceram Int 34:1297-1301. https://doi.org/10.1016/j.ceramint.2007.03.012

169. Eichler J (2012) Industrial applications of Si-based ceramics. J Korean Ceram Soc 49(6):561-565. https://doi.org/10.4191/kcers. 2012.49.6.561

170. Yan C, Liun R, Cao Y, Zhang C, Zhang D (2014) Preparation and properties of $3 \mathrm{D}$ needle-punched $\mathrm{C} / \mathrm{ZrC}-\mathrm{SiC}$ composites by polymer infiltration and pyrolysis process. Ceram Int 40:1096110970. https://doi.org/10.1016/j.ceramint.2014.03.099

171. Araia Y, Inoueb R, Gotoc K, Kogo Y (2019) Carbon fiber reinforced ultra-high temperature ceramic matrix composites: A 
review. Ceram Int 45:14481-14489. https://doi.org/10.1016/j. ceramint.2019.05.065

172. Li Z, Xiao P, Xiong X, Huang B-Y (2013) Preparation and tribological properties of $\mathrm{C}$ fibre reinforced $\mathrm{C} / \mathrm{SiC}$ dual matrix composites fabrication by liquid silicon infiltration. Solid State Sci 16:6-12. https://doi.org/10.1016/j.solidstatesciences.2012. 10.007

173. Zhoua J, Almansour AS, Chasea GG, Morscher GN (2017) Enhanced oxidation resistance of $\mathrm{SiC} / \mathrm{SiC}$ minicomposites via slurry infiltration of oxide layers 37(10):3241-3253. https://doi. org/10.1016/j.jeurceramsoc.2017.03.065

174. Silva MV, Stainer D, Al-Qureshi HA, Montedo OR, Hotza D (2014) Alumina-based ceramics for armor application: mechanical characterization and ballistic testing. J Ceram 2014:1-6. https://doi.org/10.1155/2014/618154

175. Prasad VCS (1988) Thin ceramics for electronics. Trans Indian Ceram Soc 47(2):25-35. https://doi.org/10.1080/0371750X. 1988.10822881

176. Zou C, Zhang C, Li B, Cao F, Wang S (2012) Improved properties and microstructure of porous silicon nitride/silicon oxide composites prepared by sol-gel route. Mater Sci Eng A 556:648652. https://doi.org/10.1016/j.msea.2012.07.042

177. Yasseri M, Jauß T, Sorgenfrei T, Cröll A (2019) An investigation of the wetting behavior of heat-treated silicon nitride particles with liquid silicon. J Cryst Growth 516:1-9. https://doi.org/10. 1016/j.jcrysgro.2019.03.013

178. Plaisantin H, Jacques S, Danet J, Camus G, Delpouve H (2021) TEM characterization of turbostratic and rhombohedral BN interphases synthesized by chemical vapour infiltration in $\mathrm{SiC} /$ SiC-Si composites. Mater Charact 172:110857. https://doi.org/ 10.1016/j.matchar.2020.110857

179. Ye F, Zhang L, Yin X, Liu X, Liu Y, Xue J, Cheng L (2013) SiCN-based composite ceramics fabricated by chemical vapor infiltration with excellent mechanical and electromagnetic properties. Mater Lett 111:169-172. https://doi.org/10.1016/j.matlet. 2013.08.082

180. Maa B, Zhua Y, Wang K, Sun Z (2018) PIP process greatly influencing the microstructure and electrical conductivity of polymerderived SiCN ceramics. J Alloys Compd 784:1084-1090. https:// doi.org/10.1016/j.jallcom.2019.01.102

181. Zhang H, Yang Y, Liu B, Huang Z (2019) The preparation of SiC-based ceramics by one novel strategy combined 3D printing technology and liquid silicon infiltration process. Ceram Int 45(8):10800-10804. https://doi.org/10.1016/j.ceramint.2019.02. 154

182. Servadei F, Zoli L, Galizia P, Vinci A, Sciti D (2020) Development of UHTCMCs via water based ZrB2 powder slurry infiltration and polymer infiltration and pyrolysis. J Eur Ceram Soc 40(15):5076-5084. https://doi.org/10.1016/j.jeurceramsoc.2020. 05.054

183. Zhou H, Ni D, He P, Yang J, Jianbao Hu, Dong S (2017) Ablation behavior of $\mathrm{C} / \mathrm{C}-\mathrm{ZrC}$ and $\mathrm{C} / \mathrm{SiC}-\mathrm{ZrC}$ composites fabricated by a joint process of slurry impregnation and chemical vapor infiltration. Ceram Int 44(5):4777-4782. https://doi.org/10.1016/j. ceramint.2017.12.062

184. Li L, Wang Y, Cheng L, Zhang L (2011) Preparation and properties of 2D C/SiC-ZrB2-TaC composites. Ceram Int 37:891-896. https://doi.org/10.1016/j.ceramint.2010.10.033

185. Baux A, Jacques S, Allemand A, Vignoles GL, David P, Piquero T, Stempin MP, Chollon G (2021) Complex geometry macroporous $\mathrm{SiC}$ ceramics obtained by $3 \mathrm{D}$-printing, polymer impregnation and pyrolysis (PIP) and chemical vapor deposition (CVD). J Eur Ceram Soc 41:3274-3284. https://doi.org/10.1016/j.jeurc eramsoc.2021.01.008

186. Rongjun Liu Fu, Wang JZ, Chen J, Wan F, Wang Y (2021) Effects of CVI SiC amount and deposition rates on properties of $\mathrm{SiCf} / \mathrm{SiC}$ composites fabricated by hybrid chemical vapor infiltration (CVI) and precursor infiltration and pyrolysis (PIP) routes. Ceram Int 47:26971-26977. https://doi.org/10.1016/j. ceramint.2021.06.110

187. Tong Y, Bai S, Chen $\mathrm{Ke}$ (2012) C/C-ZrC composite prepared by chemical vapor infiltration combined with alloyed reactive melt infiltration. Ceram Int 38:5723-5730. https://doi.org/10.1016/j. ceramint.2012.04.017

188. Fan X, Yin X, Wang L, Cheng L, Zhang L (2013) Processing, microstructure and ablation behavior of $\mathrm{C} / \mathrm{SiC}-\mathrm{Ti} 3 \mathrm{SiC} 2 \mathrm{com}-$ posites fabricated by liquid silicon infiltration. Corros Sci 74:98105. https://doi.org/10.1016/j.corsci.2013.04.029

189. Jiang Y, Ye C, Hongqiang Ru, Wang W, Zhang C, Yue X (2018) Oxidation protective MoSi2-SiC-Si coating for graphite materials prepared by slurry dipping and vapor silicon infiltration. Ceram Int 44(5):5171-5178. https://doi.org/10.1016/j.ceramint. 2017.12.122

190. Chen X, Feng Q, Zhou H, Dong S, Wang J, Cao Y, Kana Y, Ni D (2018) Ablation behavior of three-dimensional Cf/SiC-ZrC-ZrB2 composites prepared by a joint process of sol-gel and reactive melt infiltration. Corros Sci 134:49-56. https://doi.org/10.1016/j. corsci.2018.02.011

191. Belitskus D (1989) Fabrication processes for ceramic composites. Mater Des 10(1):2-9. https://doi.org/10.1016/0261-3069(89) 90028-9

192. Colomban P, Wey M (1997) Sol-gel control of matrix netshape sintering in 3D fiber reinforced CMCs. J Eur Ceram Soc 17(12):1475-1483. https://doi.org/10.1016/S0955-2219(97) 89406-X

Publisher's note Springer Nature remains neutral with regard to jurisdictional claims in published maps and institutional affiliations. 